Asociación de Jóvenes Historiadores y Arqueólogos de Murcia

PANTR REL

REVISTA DE CIENCIA

$$
\begin{array}{r}
Y \\
\text { DIDÁCTICA } \\
\text { DE LA HISTORIA } \\
\text { III - } 2^{2} \text { época }
\end{array}
$$




\section{ASOCIACIÓN DE JÓVENES HISTORIADORES Y ARQUEÓLOGOS DE MURCIA}

\section{PANTA REI. REVISTA DE CIENCIA Y DIDÁCTICA \\ DE LA HISTORIA III. $2^{a}$ época}


CONSEJO EDITORIAL: LAURA ARIAS FERRER

ALEJANDRO EGEA VIVANCOS

ANTONINO GONZÁLEZ BLANCO

RAFAEL GONZÁLEZ FERNÁNDEZ

JOAQUÍN LOMBA MAURANDI

ENRIQUE QUINTANA CIFUENTES

GONZALO MATILLA SÉIQUER

JOSÉ ANTONIO MOLINA GÓMEZ

REDACTOR JEFE:

ÁNGEL LUIS GONZÁLEZ TORRES

Depósito legal: MU-966-1995

I.S.S.N. 1136-2464

Edición de Compobell, S.L. Murcia 


\section{ÍNDICE}

AGRADECIMIENTOS

Presentación

Por Alejandro Egea Vivancos, Laura Arias Ferrer

\section{ARTÍCULOS}

Análisis microscópico de la industria lítica: la traceología

Por Ignacio Martín Lerma

Reflexiones en torno al estudio de la economía en Prehistoria

Por Valentín Martínez García

Aplicaciones SIG en el análisis de las sociedades del pasado. Un caso de estudio: Las primeras comunidades campesinas del Levante Peninsular

Por Gabriel García Atiénzar

La situación actual de los estudios de egiptología en España

Por José Javier Martínez García

La vida cotidiana en el Imperio Asirio. Usos y costumbres de un pueblo que conquistó las Cuatro Regiones del Mundo

Por Ángel Luis González Torres

Las formas de intercambio y las estructuras comerciales orientalizantes en la Vega Baja del Segura: dos variables de estudio arqueológico

Por Sara Pernas García 
Evolución de los patrones de asentamiento en época ibérica. Una propuesta de estudio del mundo ibérico murciano a través del análisis del poblamiento

Hispania Tierra de Roma. Organización y gestión del suelo

Por $M^{a}$ Carmen Santapau Pastor

Hacia una arqueología de la España bizantina. Breves notas a propósito del seminario Work in progress

Por Jaime Vizcaíno Sánchez

Reflexiones acerca de un estudio sobre las estancias auxiliares en la arquitectura barroca catedralicia

Por Francisca del Baño Martínez

La investigación sobre fisiognomía y expresión de las pasiones. Objetivos y metodología

Por María del Mar Albero Muñoz 


\title{
LAS FORMAS DE INTERCAMBIO Y LAS ESTRUCTURAS COMERCIALES ORIENTALIZANTES EN LA VEGA BAJA DEL SEGURA: DOS VARIABLES DE ESTUDIO ARQUEOLÓGICO
}

\author{
Sara Pernas García"
}

\section{Resumen}

En estas líneas vamos a tratar dos variables de estudio arqueológico vinculadas a la esfera económica de las poblaciones del I milenio a. C. en la fachada oriental de la P. Ibérica, las formas de intercambio y las estructuras comerciales. Cómo han sido estudiadas sus manifestaciones, a partir de qué modelos teóricos se han establecido sus interpretaciones. Se pretende analizar una problemática general a partir de un ejemplo concreto, el estudio de las manifestaciones arqueológicas dentro de un espacio geográfico muy específico, la desembocadura del río Segura, que nos sirve de laboratorio de ensayo para analizar las estructuras económicas, comerciales y poblacionales de las comunidades orientalizantes del Levante Meridional Peninsular durante la primera mitad del I milenio a.C.

Palabras clave: Fenómeno orientalizante, Estructura comercial, Forma de intercambio, Contacto cultural, Levante Peninsular, Desembocadura del río Segura.

* Agradecemos sinceramente la oportunidad dada por los organizadores y promotores de estas Jornadas de Work in Progress, Alejandro Egea Vivancos y Laura Arias Ferrer de participar en esta iniciativa, celebrada en el año 2006 en la Universidad de Murcia, que por desgracia, está poco generalizada en nuestro panorama universitario actual. Esta iniciativa intenta apoyar a los jóvenes investigadores y, sobre todo, nos muestra el firme compromiso de sus promotores por defender un modelo de investigación abierto, participativo y crítico, que, a través de seminarios, jornadas y encuentros de trabajo, potencie el diálogo constructivo y crítico entre investigadores. Porque de ambas esferas, del diálogo y del encuentro siempre surgen mejores ideas y soluciones. Por mantener siempre la mecha encendida, gracias. 


\begin{abstract}
At this article, we want to study the trading economy of the population of the oriental coast of «Península Ibérica» at fisrt millenium B.C., by means of two archaeological categories of protohistoric economy: the commodities of exchange and the trading structures. How they had been studied, what kind of theoric models had been stablished. We want to reexamine the general question, working on the specific exemple from the archaeological settlements of the lower part of the Segura's Valley. Furthermore, revise the interpretation of the spaciality of orientalizing process at $\mathrm{P}$. Ibérica, the changes of the definition of the Orientalizing concept, and the interpretation of this area, VBS, inside of the «orientalizing world», such as secondary area of expansion for the phoenicians of southern peninsular region. It'll be our experimental laboratory to determinate if it's posible, with archaeological arguments, support the «phoenician» model, based on colonial structure, or others, that defended a mixed economy structure at this area.
\end{abstract}

Key words: Orientalizing concept, Trading structure, Commodities of exchange, Cultural contact, Oriental coast of Peninsula Iberica, Lower part of Segura's Valley.

Este artículo trata de aproximarse a algunos de los principales interrogantes sobre el estudio de las estructuras comerciales orientalizantes en el área meridional del Levante Peninsular, cuestión muy ampliamente analizada por la investigación ${ }^{1}$ : ¿Es posible estudiar las formas de intercambio o las estructuras comerciales orientalizantes? ¿Cómo se ha hecho hasta el momento? ¿Cómo se ha estudiado el intercambio colonial en la desembocadura del Río Segura? ¿Qué tipo de economía existió a principios del I milenio a.C. en la Vega Baja del Segura? ¿Cuándo y cómo surge la economía política en la zona? ¿Es dada por la presencia fenicia o es preexistente? ¿Se da en la Vega Baja un modelo comercial similar al desarrollado en Toscanos o en Castillo de Dña. Blanca? ¿Con qué bases arqueológicas contamos para defender la existencia de un modelo económico-comercial colonial fenicio en la desembocadura del Segura?

1 O. Arteaga y M.R. Serna, «Influjos fenicios en la región del Bajo Segura», XIII C.N.A., Zaragoza, 1975, 737-750; González Prats, A., «Las importaciones y la presencia fenicia en la Sierra de Crevillente (Alicante)», 1986, pp. 279-302; Grau Mira, I. y Moratalla Jávega, J., «Interpretación socioeconómica del enclave», Bibliotheca Archaeologica Hispana; 12, Madrid, 2001, pp.189 -295; F. Sala Sellés, «La influencia del mundo fenicio y púnico en las sociedades autóctonas del Sureste peninsular», 2004, Aula Orientalis, 4, Barcelona, pp.57 y ss.; Vives-Ferrándis, J., Negociando encuentros, situaciones coloniales e intecambios en la costa oriental de la Península Ibérica (ss.VIII-VI a.C.), Cuadernos de Arqueología Mediterránea, 12, Barcelona, 2005. 


\section{Orientalizante. Situándonos en un tiempo y en un espacio: los constructos teóricos}

Orientalizante como enfoque y marco teórico hace referencia a un tiempo y a un espacio. Es una categoría conceptual creada por la investigación para definir un fenómeno histórico cultural acaecido durante el I milenio a.C. en la cuenca mediterránea, tradicionalmente asociado a los episodios de la colonización fenicia y griega ${ }^{2}$. Éste se ha descrito como una Koiné cultural que, desde finales del II milenio a.C. y la primera mitad del I milenio a.C., adoptó a nivel ideológico, artístico, tecnológico y material unas formas comunes de expresión, inspiradas o referenciadas en las sociedades próximo-orientales, de ahí el apelativo de «orientalizante» ${ }^{3}$.

\section{1. «Orientalizante» como «Mediterráneo»}

El término «orientalizante» esta estrechamente vinculado al concepto de Mediterráneo como idea espacial, como unidad no sólo geográfica sino también cultural, como un sistema integrado entre ambas orillas. El Mediterranismo como corriente interpretativa determina para la Antigüedad, la existencia de una relación formal entre las tierras y las comunidades que habitaron ambos márgenes de este mar, dentro un sistema cultural regional, la oikoumene, cuyas raíces ideológicas beben de la tradición heredada de los geógrafos grecolatinos, transpolando el modelo propuesto por Braudel y Wallerstein al estudio de este espacio en la Antigüedad ${ }^{4}$. El motor de unión o contacto referido tradicionalmente ha sido el comercio, dada la navegabilidad natural de sus aguas, así como otros determinantes geográficos, remarcando y enfatizando siempre la tendencia natural de comunicación entre su parte oriental y occidental ${ }^{5}$.

2 S. Moscati, I fenici e Cartagine. 1972; M. Almagro-Gorbea, «El mundo orientalizante en la Península Ibérica», II Congreso de Internationale de Studi Fenici e Punici, Vol. II, CNDR, 1991, 573-599; P. Rouillard, Les grecs et la peninsule iberique: du VIIIe au IV e siècle avant Jésus-Christ. Publications du Centre Pierre Paris Casa de Velászquez, Paris, 1991; S. Frankeinstein, Arqueología del colonialismo: el impacto fenicio y griego en el sur de la Península Ibérica y el suroeste de Alemania, Ed. Crítica, Barcelona, 1997, 386 p.; M $\mathrm{M}^{\mathrm{a}}$ E. Aubet, Tiro y las colonias fenicias de Occidente, Crítica, Barcelona, 1997.

3 Almagro-Gorbea, op. cit., ref. 3, 1991, pp. 573-574,; López Castro, J.L., «La colonización fenicia en la Península Ibérica: 100 años de investigación», en La colonización fenicia en el sur de la Península Ibérica. 100 años de investigación, Granada, 1992, pp. 11-80.

4 Horden, P. and Purcell, N., The Corrupting Sea The Corrupting Sea: A Study of Mediterranean History, 2000.

5 No obstante esta tendencia ha recibido numerosas críticas. Bowersock señala que: «the habit of orientating study of ancient Mediterranean into East and West presupposes a meaningful interpretation of Mediterranean history is questionable», vid. G.W. Bowersock, «The East-West orientation of Mediterranean Studies and the meaning of North and South in Antiquity» en Rethinking the Mediterranean, Oxford Press, London, 2006, pp. 168; W. V. Harris, «The Mediterranean and Ancient History» IBIDEM., London, 2006, pp.4. 
Relecturas posteriores defienden posturas menos unitaristas de este primer sistema cultural panmediterráneo ${ }^{6}$. Enfatizan la existencia de diversas realidades históricas, marcos más limitados, en los cuales el nexo de unión entre zonas se realizaría a través de los recursos locales y los intercambios a corta distancia, con el fin de solucionar las necesidades vitales de un área con su entorno inmediato, no pudiéndose explicar de manera total los procesos de integración cultural en el área sólo atendiendo a causas generalistas. Determinaría en definitiva una compartimentación geográfica de los estudios y aproximaciones arqueológicas, de variada y diversa amplitud, dada la existencia de varios Mediterráneos: el Occidental, el Oriental, el Central, o incluso una visión a menor escala delimitada por sus mares (el Adriático, el Egeo, etc.), por sus fachadas costeras (Levante Peninsular), u otras lecturas espaciales menores?

\subsection{Fenómeno orientalizante como constructo teórico}

El Fenómeno orientalizante como tal es un constructo histórico, un modelo teórico, creado, pensado y concebido dentro de un marco científico e ideológico contemporáneo, cuya formulación tiene su propia historicidad, que entronca consustancialmente con una tradición arqueológica nacida al amparo de discursos ideológicos de corte colonialista y eurocéntrico, que han sido englobados bajo el término de Orientalismo. ${ }^{8}$

Si bien lo «oriental» $\mathrm{y}$ «orientalizante» como términos no fueron aplicados por la investigación protohistórica peninsular hasta finales de los años 50; los estudios historiográficos sobre la arqueología orientalizante sitúan su arranque al menos en el s. XIX, definiendo lo «orientalizante» desde una perspectiva tecnológica dentro de modelos difusionistas y migracionistas, en la cual lo oriental hace referencia a objetos de fabricación importados por «colonos orientales o fenicios» a la P. Ibérica atraídos por los metales de Occidente, mientras lo «orientalizante», sería la copia local de estos modelos externos ${ }^{9}$.Proponen la existencia de tres grandes etapas en la interpretación de lo orientalizante ${ }^{10}$.

6 Harris, op. cit., ref. 6, 2006, pp. 23-25.

7 D. Abulafia, 2006, «Mediterraneans», en Rethinking the Mediterranean, Oxford Press, London, 2006, pp.67-75.

8 Harris, op. cit., ref. , 2006, pp. 2; E. Said, Orientalismo, 2003.

9 García y Bellido, A., Fenicios y cartagineses en Occidente, Madrid, 1942; J.M. Blázquez, «Tres arqueólogos españoles del siglo XX: «Los profesores A. García y Bellido, A. Blanco y J. Maluquer de Motes», VII Jornadas de Arte. Historiografía del arte español en los siglos XIX y XX, Madrid, 1995, 192-193.

10 J.M. Blázquez, «Evolución del concepto orientalizante en los últimos 50 años de investigación hispana», en S. Celestino y J.Jimenez, Eds., El periodo orientalizante. Actas del III Simposio de Arqueología de Merida: protohistoria del Mediterraneo Occidental, Anejo de A.E.A., 35, Madrid, 2005, pp. 126-148. 
Una primera fase o «tiempo de los indicios» anclada en una aparente indefinición que perdura hasta mediados del s. $\mathrm{XX}^{11}$, siendo diversos los hitos marcados para su arranque $^{12}$; y una segunda a modo de «redescubrimiento de los fenicios» con los fundamentales hallazgos materiales a partir de los años 50 y 60 en la costa andaluza, y que en nuestra zona de estudio, se pueden paralelizar con los descubrimientos realizados a partir de los $70^{13}$. En los 80 y 90 eclosiona como disciplina moderna de estudio $^{14}$, con la introducción de nuevas metodologías y marcos teóricos (estructuralismo, funcionalismo, procesualismo) que darán lugar a la aplicación de modelos interpretativos (la precolonización, la irradiación cultural, los círculos coloniales o la colonización agrícola), que defienden en general lo orientalizante como un modelo colonial que impulsa el desarrollo de una cultura mediterránea globalizada, que unifica por primera vez ambas orillas e integra al Extremo Occidente en el sistema cultural y económico del Oriente Antiguo mediante el desarrollo de importantes redes de comercio ${ }^{15}$. La investigación protohistoria levantina se hará eco de estas teorías, renovando sus planteamientos aunque siempre desde posiciones normativistas, cuyo ejemplo para la zona de estudio es el modelo de irradiación comercial en la zona del Bajo Segura $^{16}$

11 J.L. Lopez Castro, op.cit., 1992, pp. 12-14; A. Mederos Martín, «Fenicios evanescentes. Nacimiento, muerte y redescubrimiento de los fenicios en la P. Ibérica. I (1780-1935)», Saguntum, 33, Valencia, 2001, pp. 37-48; J. Vives-Ferrándis, «Notas historiográficas sobre los estudios fenicios en el País Valenciano», A.P.L., XXVI, Valencia, 2006, pp.293-321; S. Pernas García., La investigación de la Protohistoria antigua: el caso de las comarcas centrales y meridionales del Levante Peninsular, Memoria de Licenciatura inédita, Universidad de Alicante, leída en septiembre de 2005.

12 Los primeros estudios filológicos en Época Moderna, vid. Vives-Ferrándis, op. cit., ref.12, 2006, pp. 3-4; Pernas García, IBIDEM, 2005, pp.63; la publicación de las primeras evidencias materiales fenicias en el Sureste Peninsular a finales del s. XIX, vid. López Castro, op. cit. 1992, pp. 17; Pernas García, op. cit., ref.12. 2005, pp.73; el estudio artefactual o tecnológico de sus manifestaciones, vid. Blázquez, 2005, pp. 126-128, vid. Blanco, op. cit., ref.10, 1952.

13 La labor de M. Tarradell en los años 50, impulsó una revalorización con argumentos arqueológicos de la colonización fenicia en la P. Ibérica, a pesar del peso que en la disputa histórico-ideológica en esos años, entre filohelenistas y filosemitas, tenía la colonización griega, vid. Pernas García, op. cit. 2005 , pp. 83, 93. Por ello en la investigación levantina se negaba la presencia fenicia en la fachada Oriental de la P. Ibérica, zona de influjos mediterráneos de ascendencia griega, vid. Vives, op.cit.2006, pp.8; D. Fletcher, «La Edad del Hierro en el Levante español». IV Congreso Internacional de Ciencias Prehistóricas y Protohistóricas, Madrid, 1954, pp.10.

14 López Castro, op. cit, 1992, pp. 43-66; Pernas García, 2005, pp. 101-103;

15 M. Almagro-Gorbea, «Arqueología e Historia Antigua: el proceso proto-orientalizante y el inicio de los contactos de Tartessos con el Levante Mediterráneo», Anejos de Gerión, 2, 1989, pp. 277-288; Moscati, op. cit., 1972; O. Arteaga,» Perspectivas espacio-temporales de la colonización fenicia occidental. Ensayo de aproximación», Iberos, I Jornadas sobre el Mundo Ibérico, Jaén, 1986, pp. 225-228; Aubet, op. cit., 1997; C.G. Wagner y J. Alvar, «Fenicios en Occidente: la colonización agrícola», RSF XVII, 1989, pp. 61-102.

16 A. González Prats, «La presencia fenicia en el Levante Peninsular y su influencia en las comunidades indígenas», IV Jornadas de Arqueología fenicio-púnica, Ibiza, 1991, 109 -118. 
La tercera y última fase, iniciada desde fines de los 90, realiza una crítica posmoderna y replantea los modelos teóricos aplicados, constatada la esterilidad de los modelos binarios para el estudio de las dinámicas socio-culturales protohistóricas. Actualmente se esta analizando el grado y forma de integración de este sistema cultural, entendiendo la colonización fenicia del Mediterráneo Occidental como un sistema cultural propio alejado de los binomios propios de modelos coloniales contemporáneos. En esta «mediterraneización», los «fenicios» y los «indígenas» entendidos como poblaciones heterogéneas, desarrollan un complejo sistema de integración socioeconómica, que dará lugar a una relectura propia de sus manifestaciones culturales, que no serán ni orientalizantes, ni fenicias, ni griegas en estricto sentido, sino una amalgama cultural que transforma y reinterpreta inspiraciones de muy diverso origen $^{17}$.

\subsection{Un espacio: la geografía orientalizante}

El espacio orientalizante ha sufrido una evolución conceptual dentro de la investigación peninsular, entendiendo esta demarcación espacial, la geografía orientalizante, como un fenómeno cultural en el cual el determinismo físico y natural de las regiones históricas necesita de elementos socio-económicos y culturales para definir su especificidad explícita. En este sentido, la materialidad arqueológica de la presencia «fenicia» no es tanto un problema de registro como de lectura arqueológica del mismo. Esta divergencia, quizás meramente metodológica ha marcado la existencia de diferentes «geografías orientalizantes» ${ }^{18}$.

\section{- El espacio «orientalizante» andaluz:}

El punto de partida fue fijado desde finales del s. XIX y las primeras décadas del s. $\mathrm{XX}$, por las noticias mencionadas en las fuentes clásicas que hablaban de una antigua fundación fenicia en Cadiz en torno al s. XII a.C., acompañadas de hallazgos materiales puntuales que venían a confirmar la existencia de contactos «orientales». Estas teorías fueron ampliamente fundamentadas a partir de los 50 y 60, con la eclosión de la materialidad arqueológica del fenómeno orientalizante en el Sur Peninsular, que

17 Vives, op. cit. 2005; Sala, op. cit., 2004; J. Moratalla, «El territorio Meridional de la Contestania», La Contestania Ibérica, 20 años después, Alicante, 2005a, pp.91-117; Pernas García, op. cit., 2005.

18 La extensión y localización de la colonización fenicia de la P. Ibérica tuvieron una plasmación cartográfíca de sus límites geográfico, según la dispersión espacial de los hallazgos en cada momento. Estas aproximaciones marcaban una áreas preferentes y unos espacios vacíos, marginados de estos procesos históricos que la investigación actual ha podido «rellenar», vid. varios artículos en F. J. Jiménez Avila y S. Celestino Pérez (coord.), El periodo orientalizante: Actas del III Simposio Internacional de Arqueología de Mérida, Protohistoria del Mediterráneo Occidental, Mérida, 2005. 
venía a confirmar las noticias clásicas. Contribuyeron a crear algunos de los principales clichés interpretativos sobre la espacialidad de la colonización fenicia de la P. Ibérica tales como que la presencia fenicia se circunscribía a las áreas costera; que no existía presencia fenicia en áreas periféricas como el NW, el Levante ${ }^{19} \mathrm{o}$ la fachada atlántica; que la franja NE estaba bajo otra esfera de influencia esclusivamente griega; que los contactos con el interior se realizaban de forma indirecta con la presencia de «agentes fenicios» intermitentes en estas áreas, dando así una explicación simplista a la creciente presencia de materiales orientalizantes en esas áreas.

\section{- La «fiebre orientalizante» o la generalización del espacio orientalizante}

La espectacularidad y relevancia de todos estos hallazgos peninsulares significaron en la segunda mitad del s. XX, el inicio de una «fiebre orientalizante» en la cual se amplió el prisma espacial de búsqueda a estas áreas periféricas o marginales. Desde fines de los años 60 y sobre todo los espectaculares hallazgos de las décadas siguientes demostraron que «quién busca encuentra». En los 90 el mapa había variado notablemente, asistiendo a un rellenado espacial de esa «geografía de lo orientalizante», que no obstante argüía la existencia de diferencias cronológicas, que distinguían entre un área nuclear, la costa andaluza con el epicentro gaditano, y áreas expansivas como el Levante o Portugal ${ }^{20}$.

\section{- La Península Ibérica como geografía orientalizante}

En el s. XXI, la ingente acumulación de nuevos datos y la relectura de hallazgos antiguos muestra la necesidad de replantear los criterios espaciales esta geografía orientalizante con extensión peninsular. Debería revisarse esta incidencia «orientalizante» dentro de las lecturas arqueológicas regionales, a fin de definir su naturaleza en cada área, sin tener que asumir a priori, una lectura poblacional o etnica de lo fenicio u orientalizante frente a lo indígena o local, ya que asistimos a procesos de hibridación cultural, que pueden ser cognoscibles por la investigación arqueológica ${ }^{21}$.

\subsection{La geografía «orientalizante» de la Vega Baja del Segura}

El área de la Vega Baja del Segura ejemplifica un caso paradigmático dentro de este espacio orientalizante peninsular, integración durante décadas rechazada por la investigación.

19 Frente a estas posturas, algunos autores apuntaban hipótesis a su favor, vid. H. Schubart y O. Arteaga, 1986, «El mundo de las colonias fenicias occidentales», Homenaje a Luis Siret. Cuevas del Almanzora, Sevilla.; 1984, pp. 449-521. Arteaga, op. cit., 1975.

20 A. González Prats, A., «Informe preliminar de la 4 a Campaña de excavaciones arqueológicas en la colonia fenicia de La Fonteta (Guardamar del Segura, Alicante), [http://www.labherm.filol.csic.es], acceso 29-VIII-2004, Internet-Alicante. 2000.

21 Vives, op. cit., 2005. 


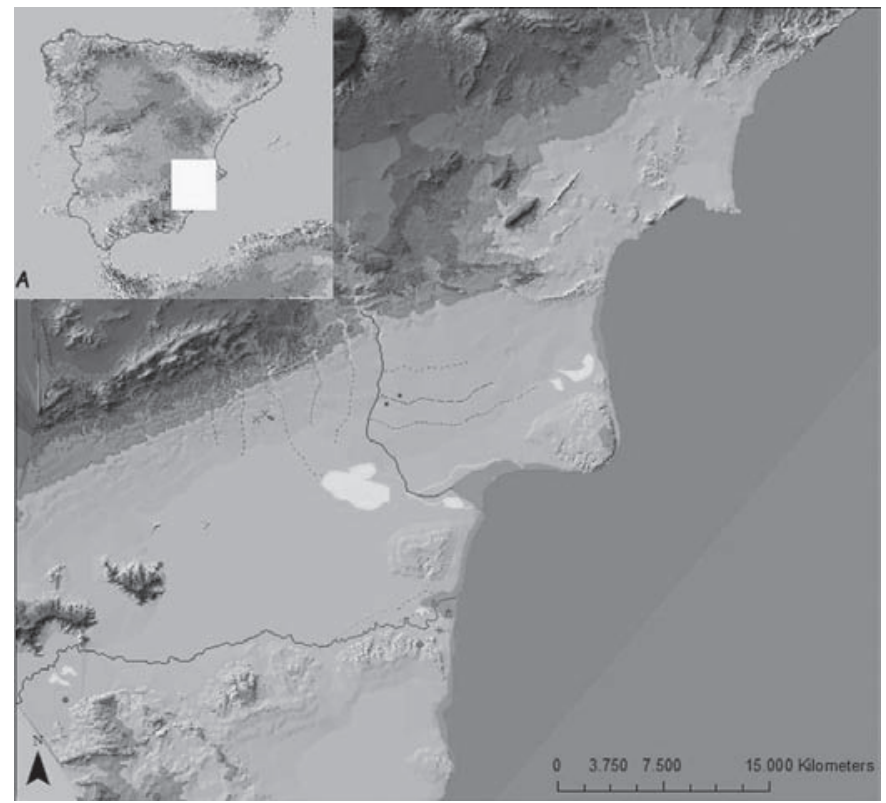

Figura 1. Zona de estudio: la Vega Baja del Segura. Elaboración propia a partir de VV.AA. ${ }^{22}$

Definida mediante criterios físicos, la Vega Baja del Segura, es un espacio bien acotado, la desembocadura del río Segura y por extensión su cuenca fluvial inferior ${ }^{23}$, situado en el área meridional de la fachada oriental de la P. Ibérica. Es una zona que cuenta con una rica tradición investigadora. No obstante, los prismas de aproximación han sido diversos, y en pocos casos se ha aplicado el estudio arqueológico territorial como línea de aproximación ${ }^{24}$. Frente a lecturas muy concretas, circunscritas al

22 Reconstrucción de la línea de costa a partir de las propuestas de Rouillard, 2007 y A.M. Blázquez, J. Usera, G. Ferrer, «Foraminíferos fósiles de un sondeo de la albufera cuaternaria de Elche-Sta Pola (Alicante, España): paleoecología e interpretación medioambiental», Geoarqueología i Quaternari Litoral, Memorial Pilar Fumanal, Valencia, 1999, pp. 309-320.

23 Se trata de un área bien delimitada geográficamente, la depresión meridional del río Segura-Vinalopó, área de contacto de ambas cuencas fluviales, confluencia dominada por un paisaje de llanura con marismas y estuarios delimitados por suaves relieves circundantes, con óptimas condiciones de comunicación y asentamiento. Recientes estudios paleogeográficos han permitido conocer una diferente configuración de la desembocadura del río Segura, mostrando la existencia de un paleoestuario actualmente colmatado, que perfila el entorno del asentamiento de la Fonteta como un pequeño promontorio costero. Para profundizar en su descripción, ver Rouillard, 2001; y Rouillard et alii, op. cit, 2007.

24 L. Abad y F. Sala (Eds.), El poblamiento ibérico del Bajo Segura, Publicaciones del Gabinete de Antigüedades de la R.A.H., Bibliotheca Arcaheologica Hispana; 12, Madrid, 2001, pp. 189-195.; Grau y Moratalla, op. cit., 2001; Moratalla, op. cit., 2004. 
estudio de yacimientos en concreto $^{25}$, existen estudios de síntesis, así como estudios territoriales de carácter comarcal o intercomarcal destacando recientemente estudios que aplican un prisma regional mucho más amplio, eludiendo los marcos administrativos, y denunciando la necesidad de ampliar los análisis a áreas vecinas próximas ${ }^{26}$. Entre estos estudios destaca una aproximación desde el «Sureste», que relaciona el panorama arqueológico de la desembocadura del Segura con toda su cuenca y afluentes, así como con la del Vinalopó, insistiendo en la necesidad de analizar conjuntamente el poblamiento protohistórico de la zona meridional de Alicante y el Norte de Murcia, «ambas provincias vertebradas geográficamente y culturalmente por el río Segura», incluyendo «también la zona del sureste de Albacete por donde discurrre el río Mundo, afluente del Segura» ${ }^{27}$. Una segunda propuesta, con diferente orientación geográfica, una aproximación «levantina», que selecciona unos límites geográficos imprecisos entre el río Ebro y el río Segura, limitando el análisis espacial eminentemente a zonas costeras, que señala una clara diferenciación de las manifestaciones y dinámicas culturales de la zona más meridional ${ }^{28}$.

La geografía orientalizante de la VBS debe ser definida por una ambivalencia de criterios: por unidades geográficas bien delimitadas con vínculos naturales entre comarcas, como sus vías de comunicación natural, siendo los valles fluviales unidades en si mismas, puentes de comunicación entre la cabecera y su desembocadura, tal y como los estudios sobre la Edad del Bronce ${ }^{29}$. Es ineludible el estudio comparativo de sus realidades costeras e interiores a fin de poder definir líneas o estructuras de poblamiento y tendencias de contacto, interacción e intercambio entre áreas.

Además este espacio de la Vega Baja del Segura (VBS) nos permite analizar cómo la investigación arqueológica ha construido o definido una geografía orientalizante, enfocada desde puntos de vista diferenciados según los modelos aplicados por diversos autores, quedando para unos integrada dentro de la geografía colonial de los asentamientos o enclaves fenicios meridionales ${ }^{30}$; o según otros investigadores

25 A. González Prats, (1983): Estudio arqueológico del poblamiento antiguo de la Sierra de Crevillente (Alicante). Anejo I de Lucentum, Universidad de Alicante, Alicante, 1983; Nueva luz sobre la protohistoria del Sudeste. Universidad de Alicante, Alicante, 1990; op. cit., 1992.

26 Abad et alii, op. cit., 2001; Grau y Moratalla, op. cit. 2001; Sala, op. cit. 2003; Moratalla, op. cit., 2004.

27 La Dra. Sala, señala en su definición del término Sureste el peso de la orografía en la delimitación de distintos «territorios» diferenciados «que enmarcan contactos culturales distintos»: uno meridional, que incluiría los Valles de Almería; otro interior y septentrional que incluiría la propia cuenca del Segura y sus afluentes; y otro costero, la franja costera de Cartagena hasta las comarcas meridionales alicantinas, Sala, op. cit., 2003, pp. 58-60.

28 Vives, op. cit., 2005.

29 M. S. Hernández Pérez, «El agua que fecunda la tierra: Uso y gestión del agua en la Prehistoria del Sureste», La cultura del agua en la cuenca del Segura, Antonio Gil Olcina (dir.), 2004, pp. 45-58.

30 González Prats, 2000; 2005 
siendo reflejo de un espacio protohistórico regional en el cual la presencia fenicia complementaria o impulsaría la construcción de un nuevo espacio cultural a lo largo de los s. VII y VI a.C. como preámbulo del mundo ibérico posterior ${ }^{31}$.

Hasta mediados de los años 70 del s. XX esta zona queda relegada del fenómeno orientalizante y por tanto de su área espacial de estudio. En esos años la investigación regional desarrollaba un intenso debate sobre la génesis de lo ibérico gracias a la influencia directa griega, dada la defensa la existencia de «colonias» en la costa alicantina como Hemeroskopeion; o la influencia púnica, con posturas que defienden la importancia del papel «punico» en lo ibérico ${ }^{32}$. Posteriormente, con el acicate de fundamentales descubrimientos en la costa levantina como Vinarrragell, en la costa castellonense, se producen dos hitos fundamentales para un cambio de interpretación. Uno, la documentación de una secuencia estratigráfica con materiales de raigambre fenicia u oriental en el yacimiento oriolano de Los Saladares desde mediados de los 70; y otro, el descubrimiento y excavación del poblado protohistórico de la Penya Negra, en Crevillente ${ }^{33}$. Varios estudios de síntesis marcan la incorporación espacial de la zona al fenómeno orientalizante por parte de la investigación protohistórica ${ }^{34}$. La profundización en el estudio de las evidencias materiales del horizonte «orientalizante» de la PNII, muestra una ingente presencia de materiales de tipo fenicio cuya zona de procedencia principal es la costa malagueña e ibicenca, así como una destacada producción local ${ }^{35}$. En este momento se configurará un modelo interpretativo por el

31 Vives, op. cit., 2005; Rouillard et alii, 2008.

32 J. Lafuente, «Importante hallazgo arqueológico.¿Una necrópolis cartaginesa?. Primeras impresiones», Noticiero del Lunes, Alicante, 1928, p.482; «La necrópolis ibérica de El Molar (Provincia de Alicante)», B.R.A.H., 94, Madrid, 1929, pp. 617-632; Alicante en la Edad Antigua, Alicante, 1957. Figueras Pacheco, F. Figueras Pacheco, Historia de Guardamar del Segura en la Edad Antigua. I. E.A. Alicante, 1957; M. Tarradell, El País Valencià del Neolítico a la iberización, Anales de la Universidad de Valencia, vol. XXXVI, q. II, Valencia, 1962-1963; SENENT IBÁÑEZ, J.J., «En torno a Hemeroskopeion», C.A.S.E., III. Murcia, Cartagena, 1948 pp. 241-243; G. Martín, La supuesta colonia griega de Hemeroskopeion. Estudio arqueológico de la zona de Dénia-Jávea. P.L.A.U.V., 3, Valencia, 1968.

33 Vives-Ferrándiz, op. cit., 2005; A.González Prats, «Balanç de vint-i-cinc anys d'investigació sobre la influència i presència fenícia a la provincia d'Alacant», Dossier, Fenicis i Púnics als Paísos Catalans, Ramon Torres, J. (Coord.), Fonaments, 12, 2005, pp. 41-64; «Presencia fenícia al País Valencià: novetats i balanç provisional», Fonaments, 8, 1992, pp. 171-182; O. Arteaga y M. R. Serna, «Los Saladares: un yacimiento proto-histórico en la región del Bajo Segura», Crónica del XII CNA, 1973, pp. 437-450; A. González Prats, «El Tesorillo de tipo orientalizante de la Sierra de Crevillente», Ampurias, 38-40, Barcelona, 1976, pp. 349-360; «El componente tipológico griego en el ambiente cerámico de Peña Negra II (675 - 550 a.C.)», Lucentum, I, Alicante, 1982, pp. 93-113; op. cit., 1983; «Los nuevos asentamientos del final de la Edad del Bronce: problemática cultural y cronológica», Arqueología del País Valenciano: Panorama y perspectivas. Edición internet. Valencia, 1985.

34 E.A. Llobregat Conesa, «Orígenes de la cultura ibérica en la Contestania», Ampurias, 38-40, Simposi Internacional Els Origens del món ibèric, 1976-1978, pp. 61-74.

35 Gonzalez y Pinna, op. cit. 1983; González Prats, op. cit., 1983. 
cual la VBS será una zona de expansión secundaria de la denominada «colonización fenicia», siendo incluida en las síntesis y ensayos generales sobre el periodo ${ }^{36}$.

La detección de cerámicas de tipo «fenicio» en las inmediaciones de las Dunas de Guardamar, a mediados de los 80, marcará el inicio de la tercera fase de esta «aprenhensión» espacial orientalizante: el descubrimiento del yacimiento de La Fonteta en la desembocadura del citado río, que venía a confirmar anteriores hipótesis de la existencia de una presencia fenicia directa en la zona ${ }^{37}$. No obstante, el desarrollo de proyectos de excavación sistemática en La Fonteta no llegará hasta finales de los 90 y sobre todo en los primeros años del s. XXI. Estos trabajos, han sacado a la luz un complejo y rico panorama arqueológico e interpretativo respecto a lo orientalizante, en el cual, a medida que se profundiza en su conocimiento ${ }^{38}$, se va configurando como uno de los mejores ejemplos peninsulares para enfrentarnos a un debate abierto y crítico sobre los modelos teóricos e interpretativos asumidos durante más de 50 años sobre la colonización fenicia de la P. Ibérica ${ }^{39}$. Con lo cual podemos señalar que la dificultad interpretativa de muchos puntos detectados en la VBS dentro de los marcos hasta ahora definidos o la dificultad para asimilar algunos datos arqueológicos con los esquemas interpretativos de otras áreas, hablan sin duda, una de sus más loables cualidades.

Existen varias formulaciones interpretativas sobre el fenómeno orientalizante en la VBS:

- un primer modelo, en el cual la ecuación colonial - la colonia fenicia costera, la Fonteta, junto a asentamientos de tipo fenicio, Castillo de Guardamar y Cabezo de l'Estany, formarían un importante complejo urbano y territorial fenicio en la desembocadura, completado con la existencia en algunos enclaves orientalizantes de presencia directa fenicia, como en el complejo de la Penya Negra - ha servido para defender la existencia de un nuevo foco de presencia

36 Aubet, op. cit. 1994.

37 R. Azuar, 1989, La Rábita califal de la Rábita de Guardamar (Alicante). Cerámica, Epigrafía, Fauna, Malacofauna. Diputación Provincial de Alicante. Alicante, 1989; Schubart y Arteaga, op. cit., 1986.

38 Además el desarrollo de proyectos de prospección intensiva, vid. Rouillard et alii, 1998; y excavación, vid. A. García Menarguez, «El Cabezo Pequeño del Estaño, Guardamar del Segura. Un poblado protohistórico en el tramo final del río Segura», Actas del coloquio El mundo púnico. Historia, sociedad y cultura. Biblioteca básica murciana: extra 4, Cartagena, 1994, pp. 269-280, en nuevos núcleos ha determinado la existencia de un mejor y más rico registro arqueológico «orientalizante» en la zona, vid. Pernas García, op. cit., 2005.

39 Blázquez, op. cit, 2005; Sala, op. cit., 2004; Vives, op. cit. 2005; Hernández, HERNÁNDEZ PÉREZ, M. S., «La Contestania ibérica desde la prehistória»,La Contestania ibérica, 20 años después, Abad et alii, coord, Alicante, 2005. 
colonial fenicia, de cronología arcaica, asimilable al resto de núcleos peninsulares meridionales, dentro de marcos cronológicos que la sitúan como una de las áreas con presencia fenicia más antigua de la P. Ibérica ${ }^{40}$

- un segundo modelo, que interpreta la incidencia fenicia de forma menos directa dentro del contexto de organización territorial indígena. Esta organización comprendería núcleos como los asentamientos del entorno de la Penya Negra, los Saladares y otros núcleos más litorales como los poblados protohistóricos del Cabezo de l'Estany y la Fonteta, en los cuales incidiría el elemento feniciooccidental en un momento situado a lo sumo en torno a finales del s. VIII a.C. y sobre todo en el s. VII a.C. Estos últimos yacimientos, serían enclaves de contacto y/o cohabitación de poblaciones «fenicio-occidentales» y locales ${ }^{41}$.

- un tercer modelo, señala este área como ejemplo de zona de expansión feniciooccidental secundaria del Círculo del Estrecho-costa malagueña- a finales del s. VIII y sobre todo el s. VII a.C. que estaría caracterizada por un concepto de asentamiento fenicio costero sin las implicaciones territoriales fijadas anteriormente, que entroncaría en los términos de port of trade, marcado por el carácter híbrido y multi - étnico de este tipo de enclaves, espacio propicio para el desarrollo de fenómenos de hibridación cultural e interacción de muy diversa índole, insertado dentro de la organización socio-económica local de poblados jalonados a lo largo de la desembocadura y en las tierras situadas en los bordes de la formación de paleomarisma prelitoral, y que sin duda, serviría de acicate a la economía de la zona ${ }^{42}$.

\section{Los -ismos de la investigación arqueológica de la VBS: Orientalismo versus centroeuropeismo versus helenismo versus indigenismo}

El principal elemento de discusión en VBS respecto al fenómeno orientalizante ha sido determinar la naturaleza de la poblaciones que habitaron durante el I milenio a.C., o al menos dilucidar qué población, arqueológicamente diferenciada con componentes quasi étnicos, ${ }^{43}$ detentaba el poder de desarrollo del cambio social ${ }^{44}$. Las diferentes propuestas realizadas en algo más de un siglo de investigación protohistórica

40 González Prats, op. cit. 2005..

41 Rouillard et alii, op. cit. 2007.

42 Vives- Ferrándiz, op. cit., 2005, pp. 79-80; Vives- Ferrándiz, op. cit., 2005, pp. 182-183; op. cit. 2006.

43 González Prats, op. cit.2005.

$44 \mathrm{El}$ análisis historiográfico nos permite comprobar hasta qué punto han quedado imbricadas las lecturas culturalistas en la investigación protohistórica levantina, rasgo que ha sobrevivido y reelaborado a lo largo de las décadas, vid. Pernas García, op. cit, 2005, pp. 
sobre la Edad del Hierro han virado hacia cuatro respuestas o tendencias destacadas: centroeuropeismo, helenismo, indigenismo u orientalismo. Analicemos el debate de estos -ismos:

En inicio, el debate se centró durante mucho tiempo en determinar la naturaleza y características del factor externo de aculturación o impulso económico-comercial como único agente que explicase el desarrollo de las sociedades indígenas del Bronce, ancladas en una atemporal Edad del Bronce Valenciano que eclosionaba, tras un hiatus de tiempo sin contenido histórico claro, en el mundo ibérico. Las primeras propuestas sólo admitían «influjos culturales eurocéntricos» de corte difusionista. Las teorías invasionistas sobre la llegada de los Campos de Urnas centroeuropeos marcaban el inicio de la Primera Edad del Hierro, en diversas oleadas o en una sola ${ }^{45}$, cuya labor de aculturación era posteriormente completada por la presencia griega directa - tal y como defendía la tradicional hipótesis sobre la existencia de colonias griegas en Alicante (Hemeroskopeion) -, la cual a partir del s. VII-VI a.C. marcaba la génesis identitaria de lo ibérico ${ }^{46}$. Frente a ello existían postulados que defendían una creciente atención hacia lo púnico e incluso lo fenicio ${ }^{47}$, así como posturas intermedias que aludían a «influjos mediterráneos» ${ }^{48}$

Otra discusión importante fue determinar la relevancia del factor interno, siempre desde una perspectiva normativista, con la discusión sobre la existencia o no de una fase de desarrollo dentro de la propia Edad del Bronce Valenciano, que permitiese argumentar la existencia de una facies del Bronce Final en Levante, es decir, poblaciones indígenas que denotaban un desarrollo diferenciado que antecedía «evolutivamente» a la etapa ibérica, tal y como establecían las secuencias y modelos euro$\operatorname{peos}^{49}$

Y como tercer paso, ante la evidencia arqueológica de yacimientos como Saladares o Vinarragell, discutir qué grupo cultural o étnico determinó la evolución social indígena, la presencia fenicia, la griega, o la indígena del Bronce Final ${ }^{50}$. F. Sala ha

45 M. Almagro-Gorbea, «El Pic dels Corbs, de Sagunto, y los campos de urnas del NE de la Península Ibérica» Saguntum, n 12, Valencia, 1977, pp. 89-144; G. Ruiz-Zapatero, «Las acciones de Campos de Urnas en el País Valenciano», C.P.A.C., 5, Castellón de la Plana, 1978, pp. 243-255.

46 C. Aranegui Gascó, «Las influencias mediterráneas al comienzo de la Edad del Hierro», Monografías del laboratorio de Arqueología de Valencia, no 1, Valencia, 1981, pp. 41-66.

47 M. Tarradell, «Sobre la última época de los fenicios en Occidente», Zephyrus IV. Homenaje a César Morán Bardón, 1953, pp. 511-515; «La cultura del Bronce Valenciano. Nuevo ensayo de aproximación», P. L. A.V., 6, Valencia, 1969; Arteaga y Serna, op. cit., 1975; M. Gil Mascarell, , «Bronce Tardío y Bronce Final en el País Valenciano», Monografías del laboratorio de Arqueología de Valencia, $\mathrm{n}^{\mathrm{o}}$ 1,Valencia, 1981, 9-39.

48 Fletcher, op. cit., 1960.

49 Gil Mascarell, op. cit., 1981; González Prats, op. cit., 1985; Pernas García, op. cit. 2005.

50 Llobregat, op. cit., 1981. 
señalado recientemente ${ }^{51}$, que tras la refutación de la tesis colonial griega en Alicante, el factor fenicio vino a situarse como el máximo actor de la génesis del proceso protohistórico regional a través de la configuración de procesos coloniales que articulaban el desarrollo económico, comercial y socio-cultural de las poblaciones peninsulares. Asumida la aseveración de que se trataba de un proceso colonial directo, entendido en su acepción más presentista tras el descubrimiento y excavación del enclave fenicio de la Fonteta, se pasó a discutir sobre cuál era ese modelo externo de economía y ocupación territorial que veía a desencadenar a nivel local el proceso de aculturación «orientalizante» desarrollado en multitud de áreas del Mediterráneo Occidental.

Dada la existencia de un destacadísimo registro «fenicio» en la Fonteta, ésta fue descrita como una colonia fenicia de época antigua con una intensa ocupación orientalizante de su hinterland, tanto en su desembocadura como en su zona prelitoral, configurándose por tanto como un área en la que se desarrollaron intensos procesos de aculturación dada la cohabitación de poblaciones fenicias e indígenas ${ }^{52}$. A principios del s. XXI, había quedado establecido un modelo de ocupación territorial y comercial colonial fenicio semejante al descrito para otros ámbitos peninsulares, como la región gaditana o malagueña, siendo integrada la VBS en las discusiones generales sobre el fenómeno colonial peninsular ${ }^{53}$. No obstante existían otras posturas interpretativas que venían a matizar este modelo ideal, sobre todo a partir de las revisiones y nuevos estudios en los últimos años ${ }^{54}$.

Actualmente, la postura revisionista está intentando superar los marcos culturalistas en la investigación, aplicando dos líneas de actuación: una metodológica y técnica, que prioriza la revisión de secuencias y materiales arqueológicos, su análisis con nuevas técnicas analíticas, el desarrollo de estudios paleogeográficos y paleobotánicos que ayuden a precisar el entorno natural de principios del I milenio a.C., la superación de modelos cronotipologistas rígidos ${ }^{55}$. Otra teórica, que hace hincapié en una lectura arqueológica desde nuevos postulados antropológicos, que rechaza la asunción de modelos interpretativos de manera acrítica, presentando otras posibles lecturas de las argumentaciones arqueológicas establecidas sobre el registro material de $\mathrm{VBS}^{56}$.

51 Sala, op. cit., 2004.

52 González Prats, op. cit., 1991.

53 Wagner, op. cit., 2000; op. cit., 2005; op.cit. 2008.

54 Rouillard et alii, op. cit., 1998; Sala, op. cit. 2003; Moratalla, op. cit., 2004, Vives, op. cit. 2005; Rouillard et alii, op. cit., 2007.

55 Vives, 2005; Rouillard et alii, op. cit., 2007.

56 Vives, op. cit., 2005. 


\section{La cuestión comercial: motor o instrumento. Hacia una definición social de los intercambios}

Dentro de la investigación protohistórica sobre los fenicios, el comercio ha sido uno de los pilares del estudio arqueológico, interpretándose tradicionalmente como el principal motor económico del mundo orientalizante, a excepción de otras posturas que defendían el desarrollo de políticas de implantación territorial como impulso económico.

Un problema de los estudios sobre las estructuras comerciales protohistóricas ha sido la aplicación de modelos interpretativos o terminologías modernas sin una reflexión previa sobre dichos conceptos, tales es el caso de términos como economía ${ }^{57}$, comercio o intercambio ${ }^{58}$. El comercio ${ }^{59}$, interpretado de forma determinista como vertebrador únicamente de intercambios con fines de enriquecimiento o subsistencia, también incluye una dimensión social en la cual existe una gran multiplicidad de transmisiones e interacciones relativas a la esfera social y cultural, ya que la realización de estos intercambios de bienes conlleva implícitamente el establecimiento de relaciones sociales e intercambios de conocimiento entre los agentes implicados en esta actividad ${ }^{60}$.

\subsection{El viejo debate sobre la economía antigua}

El comercio ha sido sin duda uno de sus caballos de batalla más polémicos y controvertidos durante la mayor parte del s. XX en la investigación de la economía protohistórica. Durante años, se desarrolló un debate sobre la definición de las es-

57 El término «Economía» entendido dentro de una acepción antropológica y social, se define como el conjunto de decisiones o actuaciones encaminadas a satisfacer unas necesidades por parte de un grupo humano, que derivan en dos esferas de acción que pueden o no solaparse. Una primera esfera, en la cual se realizan con un fin subsistencial o de consumo: para la satisfacción o provisión de elementos deficitarios. Es decir, nacen de la escasez y en ellos prevalece el valor de uso, material. Una segunda, destinada a satisfacer necesidades y aumentar la acumulación de elementos, es decir, crear riqueza, vid. T. K., Earle, «Chiefdoms in archaeological and ethnohistorical perspective», Annual Review of Anthropology, vol. 16, 1987, pp. 279-308; ed., Chiefdoms: Power, Economy, and Ideology, Homme: Revue française d'antropologie, № 137, 1996; A. W., Johnson, y T. K, Earle, La evolución de las sociedades: desde los grupos cazadores-recolectores al estado agrario, Ariel, 2003; E. Demarrais, J. Castillo, T. Earle, «Ideology, materialization and Power Strategies», Current Anthropology, Vol. 37, n 1, 1996, pp. $15-31$.

58 Lopez Castro, op. cit. 1992.

59 Como definición es la actividad económica consistente en realizar intercambios de productos o valores con fines subsistenciales o lucrativos, pero también el sistema de relaciones que se derivan de dicha tarea, vid. Johnson y Earle, op. cit, 2003.

60 A. Appadurai, «Introduction: commodities and the politics of value», en A. Appadurai, Ed., The social life of things. Commodities in cultural perspective, Cambridge University Press, 2006, pp.41-42. 
tructuras y sistemas comerciales fenicios, englobado en dos posturas enfrentadas, la sustantivista, que preconizaba unas formas, estructuras comerciales y códigos de intercambio propios para la Antigüedad, no semejantes a las estructuras económicas contemporáneas, por tanto, la inexistencia de mercado privado; y la modernista, que defendía la existencia de iniciativa privada y de la ley de la oferta y la demanda como motor de los intercambio. El elemento común de ambas posiciones ha sido interpretar este modelo comercial fenicio como un modelo socio-económico de corte colonialista, hasta el punto de que ambos conceptos, comercio fenicio y sistema colonial han sido tratados como sinónimos.

Desde los años 90 se tiende a solucionar dicha divergencia, con la defensa de una explicación multicausal como motor de ese «proceso colonial fenicio», muy complejo que aplicó múltiples modelos en su desarrollo: en unos casos, se desarrolló mediante una implantación económica a través del comercio, y en otros, con la consolidación de procesos protourbanos de aprehensión territorial por parte de los «fenicios-occidentales» en el Occidente Mediterráneo ${ }^{61}$.

En la última década, existen dos líneas de estudio incipientes: una, que defiende la necesidad de analizar las estructuras comerciales fenicias próximo-orientales a fin de entender cuál era el mundo comercial de estas poblaciones en su lugar de origen (mentalidad, costumbres, prácticas comerciales), para valorar mejor el tipo de contacto desarrollado en Occidente ${ }^{62}$. Otra, revisionista que intenta revisar la formulación de comercio colonial fenicio, atendiendo a una relectura de las evidencias arqueológicas que denotan importantes fenómenos de hibridación cultural, que ponen en tela de juicio muchas asunciones sobre el pretendido «modelo colonialista comercial» como medio de explicación del fenómeno orientalizante ${ }^{63}$.

\subsection{Los modelos comerciales}

\subsubsection{El modelo Sustantivista}

La teoría sustantivista impulsó enormemente los estudios sobre la colonización fenicia del Mediterráneo y renovó los marcos interpretativos peninsulares, excesivamente difusionistas y migracionistas todavía a principios de los años $80^{64}$. Fue desarrollada dentro de concepciones funcionalistas y sistémicas, consiguiendo una mayor capacidad explicativa, ya que coordinaba todas las esferas sociales y culturales en

61 Aubet, op. cit., 1994.

62 Sala, op. cit. 2004.

63 Vives, op. cit., 2005.

64 K. Polanyi, C. Arensberg, y H. Pearson, Comercio y mercado en los imperios antiguos, Labor. Barcelona.1976. 
La valoración del intercambio nacería de connotaciones sociales e ideológicas, establecidas en pactos y alianzas entre individuos a través de ceremoniales, expresando relaciones de igualdad, desigualdad o servicio ${ }^{97}$.

\subsection{Las estructuras del comercio}

\subsubsection{El intercambio}

En la definición de intercambio se entiende reciprocidad de servicios o actividades entre personas, organizaciones o estados, pudiendo ser equiparado ${ }^{98}$ o desigual ${ }^{99}$. El tipo de intercambio que analizaremos está insertado dentro de sistemas no monetales de trueque, que a lo sumo poseen ciertos elementos que adquirieren un valor de referencia, legitimado no sólo a través de una concepción material sino también simbólica o social de ciertos objetos ${ }^{100}$. Se solapa en dos esferas: la subsistencial (provisión y solución de necesidades vitales) y la de representatividad social o política (a través de redes de relaciones personales que posibiliten el desarrollo de estrategias económicas comunitarias).

El intercambio, entendido tanto a nivel intracomunitario como extracomunitario, ha sido considerado por la Antropología y la investigación histórica como uno de los motores principales del proceso de jerarquización social de las sociedades. Esta consideración está muy presente en los estudios orientalizantes, ya que se interpreta que el acceso a determinados bienes nuevos a través del comercio, es un indicador del desarrollo de estrategias de diferenciación social en los poblados, ya que sólo algunos tienen acceso a los nuevos materiales venidos de otras zonas del mediterráneo.

97 Los modelos antropológicos señalan que estas sociedades establecen a través de ceremoniales lazos de colaboración y respeto hacia su líder, y a su vez, en sus relaciones con los dirigentes del resto de tribus, organizan y equilibran las relaciones y competitividades entre comunidades, lo que se ha denominado como prestige-chain o cadena de prestigio, vid. C. Renfrew, 1977, «Alternative models for Exchange and spatial distribution», en Exchange Systems in Prehistory, eds, T.K. Earle y J.E. Ericsson, Academic Press, London, pp. 71-90.

$98 \mathrm{Si}$ el intercambio se establece mediante un acuerdo entre organizaciones que se sitúan en relación de igual a igual, el intercambio será igualitario, según un código de valores común aceptado por ambos.

99 Si son organizaciones desiguales entre si o bien, existe un código de valores desigual entre ambos (no expuesto explícitamente), o bien, se realiza el intercambio asumiendo el papel de dominio de una de las partes sobre la otra, el resultado es que el un intercambio desigual en el cual una de las partes sale más beneficiada del cambio, Johnson y Earle, op. cit. 2003.

$100 \mathrm{El}$ intercambio en un contexto de trueque se debe a variadas motivaciones: como valor de uso (por la capacidad funcional de ese objeto o por suplir una carencia de consumo básica), como valor de representación que puede incidir en la esfera social (prestigio ideológico), político (referente de poder) o riqueza (valor basado en la acumulación de bienes que han sido estimados por su valor de cambio o poder de adquisición), vid. Johnson y Earle, op. cit. 2003. 
una sola explicación. Además, era cognoscible a nivel arqueológico, superando la tradicional investigación sobre la colonización fenicia basada exclusivamente en las fuentes escritas. No obstante, este modelo ha sido duramente criticado ${ }^{65}$.

Las claves de esta teoría son: 1) la no existencia de comercio lucrativo por parte de los fenicios, ya que asume que éstos realizaban intercambios para suplir necesidades; 2) este intercambio es de tipo estatal, y se realiza mediante la fórmula de los tratados (Treaty Trade); 3) no existen leyes de mercado (oferta/demanda o precio) porque no existe competitividad: los precios se acuerdan en el tratado previamente; 4) los intercambios se realizan mediante grandes expediciones a larga distancia para obtención de materias primas y objetos de lujo. Es decir, defiende la existencia de una integración económica de gran alcance, asumiendo que los acontecimientos desarrollados en un extremo del Mediterráneo inciden totalmente en el desarrollo socio-económico del lado opuesto.

Sus elementos principales serían: las formas de intercambio no lucrativo como la reciprocidad ${ }^{66} \mathrm{o}$ la redistribución ${ }^{67}$, unas estructuras comerciales estatales ${ }^{68}$ y un sistema de comercio basado en valores premonetales y transacciones realizadas mediante un representante estatal o diplomático que establece acuerdos entre comunidades, es decir, un comercio administrativo ${ }^{69}$.

65 La excesiva rigidez de su planteamiento; su naturaleza «idílica», que presupone un proceso colonial «pacifico» sin conflictos ni resistencias; la inexistencia de ánimo de lucro en los intercambio de una sociedad tan desarrollada como la fenicia; es unidireccional, el comercio tiene como única finalidad el abastecimiento deficitario de materias primas como el metal; es simplista, hace prevalecer las circunstancias de la metrópolis en el desarrollo de las estructuras comerciales del Extremo Occidente, vid, D. Kaplan, «La controversia formalistas-sustantivistas de la antropología económica: reflexiones sobre sus amplias implicaciones», en Godelier, M. (coord.) ¿Es posible una Antropología económica?, Antropología y economía. Anagrama. Barcelona, 1976; Aubet, 1994.

66 Ha sido definida como la relación que establece una correspondencia mutua entre dos individuos u organismos, que denotan contraprestaciones iguales o superiores en valor. La motivación es relacional o social, de alianza, pacto o amistad, denominándose en este caso como Intercambio de dones, vid. M. Gauss, Ensayo sobre el don la forma y la razón del intercambio en las sociedades arcaicas, 1925.

67 El reparto o distribución de elementos, reunidos o acumulados previamente en un punto, vinculado con una cierta centralización política, asociado normalmente a un tipo de intercambio propio de sociedades complejas, vid. Jonson y Earle, op. cit., 2003.

68 Las estructuras comerciales que propone se caracterizarían por la existencia de: rutas de comercio a larga distancia de productos suntuarios, para los que se fletarían expediciones; una red de asentamientos comerciales o Puertos de comercio, como lugares de intercambio y firma de acuerdos, caracterizados por sus estratégicas condiciones de embarcadero y ubicación en espolones rocosos costeros en las desembocaduras de los ríos; agentes o individuos de cierto prestigio que actúan como diplomáticos y establecen acuerdos bajo un sistema de valores en el que predominan las connotaciones ideológicas o de prestigio, vid. Aubet, 1994.

69 Tipo de comercio establecido entre dos comunidades a través de sus representantes, que firman un tratado de alianza y colaboración en el que establecen las pautas, cantidad y equivalencias del intercambio previamente bajo el auspicio garante de los dioses, vid. Jonson y Earle, op. cit., 2003. 
Su aplicación arqueológica significó la defensa de una naturaleza exclusivamente comercial para los enclaves fenicios sin ocupación territorial ${ }^{70}$, definidos en dos categorías: las Factorías comerciales, puntos de escala en la navegación, de escasa población, donde se realizan los tratados ${ }^{71}$ para obtener materias deficitarias como metales; los Port of Trade, centros auspiciados por el Estado, que distribuyen productos gracias al comercio especializado a larga distancia ${ }^{72}$. Fenicios e indígenas desarrollarían una estrecha convivencia en los poblados indígenas, en los barrios de comerciantes $^{73}$, o a través de alianzas matrimoniales mixtas ${ }^{74}$.

\subsubsection{El modelo actualista}

La teoría actualista expone sus interpretaciones desde un punto de vista totalmente opuesto: valora sobre todo la preexistencia de una economía y comercio que busca el lucro. Estas tesis fueron propuestas por autores como Burling y Leclair, antropólogos y estudiosos de la historia económica como Meillassoux, Barceló ${ }^{75}$. Defiende la existencia de un sistema de mercado propio; de la ley de la oferta y la demanda y sobre todo de una cohabitación de un comercio estatal y otro privado; de valores premonetales que actuaban con el mismo papel que la moneda, y dotaban de valor abstracto al contenido de los intercambios, es decir, estableciendo precios, tarifas y equivalencias (nacidos de acuerdos o compromisos sociales), materializadas en objetos suntuarios, preferentemente metales, como lingotes de plata, thimatherion, braserillos, etc. ${ }^{76}$.

Las formas de intercambio incluirían intercambios privados entre comerciantes e individuos, realizados en lugares de intercambio o barrios de comerciantes (tipo Karum) ${ }^{77}$ a través de dichos agentes privados (tamkarum $)^{78}$.

70 VV.AA, Los fenicios en Andalucía, 1985.

71 C.H.Niemeyer, Ed., Phöenizer in West, Madrider Beïtrage, 8, Madrid, 1982; Bisi

72 Aubet, op. cit. 1994, Frankeinstein, op. cit. 1997.

73 González Prats, op. cit. 1990.

74 López Castro, op. cit, 1992.

75 U. Martínez Veiga, Antropología económica: conceptos, teorías, debates. Barcelona: Icaria, 1990.

76 González Prats, op. cit. 2000; 2005.

77 El karum próximo-oriental es un modelo de centro comercial - barrios extramuros en algunas ciudades donde se concentraban comerciantes, firmas o asociaciones de comerciantes, y en los que se realizaban las transacciones, siendo regidos por las normas de la metrópoli de origen. Comprendería las viviendas de los comerciantes, almacenes, talleres, la Casa del comercio o las sedes de Firmas, vid., Domínguez Pérez, J. C., «El «Karum» asirio como modelo de colonia comercial inicial: implicaciones teóricas sobre su aplicación a las fundaciones fenicias orientales», Revista atlántica-mediterránea de prehistoria y arqueología social, $\mathrm{N}^{\circ} 7,2004-2005$, pp. 79-107.

78 El Tamkarum, agente estatal o comerciante privado, ha sido definido como el encargado del intercambio comercial que viaja con sus mercancías y con una pequeña infraestructura Domínguez Pérez, op. cit. 2004-2005. 


\section{Los modelos comerciales durante el I milenio a.C. en la VBS: los modelos ar- queológicos}

\subsection{El modelo comercial colonial fenicio}

Este primer modelo ha sido propuesto principalmente por González Prats ${ }^{79}$ a partir del análisis de los yacimientos de la Penya Negra, Fonteta , Cabezo de l'Estany y Castillo de Guardamar entre otros, y defiende la existencia de una estructura comercial fenicia, iniciada con el establecimiento en la costa, en las proximidades de un antiguo estuario en la actual desembocadura del río Segura, de un primer establecimiento fenicio a mediados o incluso principios del s. VIII a.C., que vertebrará desde los primeros momentos un sistema de intercambio de productos y bienes en toda el área de la Depresión Meridional del Vinalopó-Segura, atraídos sin duda por la existencia de una organización poblacional y económica indígena importante en la Sierra de Crevillente y en las inmediaciones de la amplia llanura que forma en su tramo inferior el río Segura con un doblamiento de caseríos agrícolas como Los Saladares. Este modelo plantea que la presencia fenicia directa en la zona, es debida fundamentalmente, a la atracción que supone la existencia de una producción metalúrgica indígena en la zona que entronca con las producciones atlánticas ${ }^{80}$; la relativa facilidad en el aprovisionamiento de mineral metálico, llegado a través de la redistribución de metal en los circuitos regionales de intercambio, aunque incluso se llegó a plantear la posibilidad de actividades extractivas en la S. de Crevillente, o incluso en la S. Camara, en pleno Valle del Vinalopó ${ }^{81}$; así como el carácter geoestratégico del área como zona de confluencia de vías de comunicación tanto terrestres con el interior y el Sureste peninsular, fluviales con las áreas interiores de los Valles del Segura y del Vinalopó, y marítimas con otras zonas costeras.

79 González Prats, op. cit., 1983; «La Fonteta. El asentamiento fenicio de la desembocadura del río Segura (Guardamar, Alicante, España). Resultados de las excavaciones de 1996 - 1997», R. d S.F., Roma, 1999, 191 - 228; op. cit. 2000; op. cit. 2005; «Rasgos arquitectónicos y urbanísticos de La Fonteta», J.L. López Castro, Ed., Las Ciudades fenicio- púnicas en el Mediterráneo Occidental, C.E.F y P., Almería, 2008.

80 González Prats, op. cit., 1983.

81 A. Poveda Navarro, «Primeros datos sobre las influencias fenicio-púnicas en el corredor del Vinalopó (Alicante)», en A.González Blanco, J.L. Cuchillos y M. Molina (eds.): El mundo púnico. Historia, sociedad y cultura, Biblioteca Básica Murciana, Extra, 4: 489-502. Murcia, 1994; «Penetración cultural fenicia en el territorio indígena del valle septentrional del Vinalopó (Alicante)», en $\mathrm{M}^{\mathrm{a}}$. E. Aubet y M. Barthéley (eds.): IV Congreso Internacional de Estudios Fenicios y Púnicos (Cádiz 1995), IV, Universidad de Cádiz 1863-1874. Cádiz, 2000. 


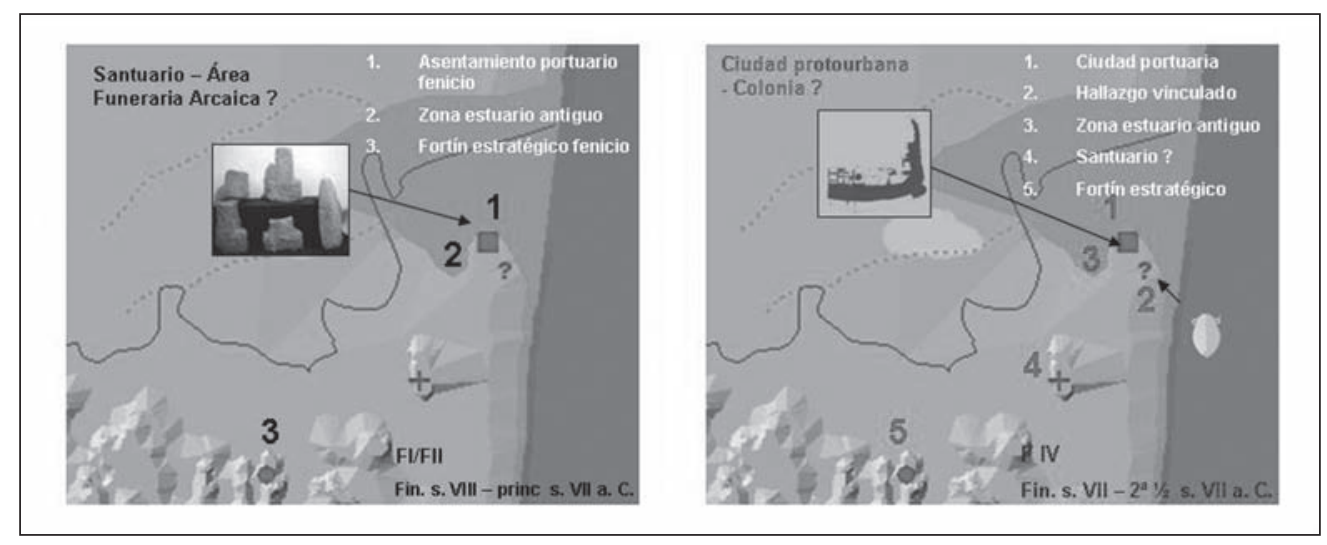

Figura 2. Modelo colonial fenicio en la desembocadura del Segura (a partir de VV.AA.).

Se desarrolla en tres áreas principalmente: Una costera, en las inmediaciones del paleoestuario del Segura, donde se ubican los asentamientos fenicios de la Fonteta, el enclave portuario, y un pequeño fortín, el Cabeço de l'Estany, cuyo papel sería controlar la zona portuario interior. Ambos enclaves cuentan con sistemas constructivos que han sido vinculados con prototipos orientales y han servido para justificar su carácter eminentemente fenicio, al incorporar sistemas constructivos como las mencionadas casamatas $^{82}$. Una prelitoral, en las inmediaciones de la S. de Crevillente, en la cual se localiza el poblado del Bronce Final de la Penya Negra, que tras el establecimiento fenicio, conocería un crecimiento sin parangón llegándose incluso a instalar un barrio de artesanos fenicios en uno de los sectores del poblado, dada la documentación de una pieza cerámica con un grafito fenicio, así como numerosas marcas de alfarero $^{83}$. Por último, una en el propio valle del Segura en la salida hacia el corredor propiamente dicho, área llana en la cual se ubican poblados indígenas como Los Saladares, que reciben tempranamente los primeros productos fenicios ${ }^{84}$.

Distingue dos grandes fases de desarrollo comercial: una Fase arcaica, desarrollada desde s. VIII a.C. hasta mediados del s. VII a.C. en la cual se desarrolla un modelo de estructura comercial de tipo sustantivista, con la presencia de un establecimiento fenicio no permanente o emporio comercial ${ }^{85}$ que cuenta con la existencia de un área

82 González Prats, op. cit., 2000.

83 González Prats, op. cit, 2005.

84 Arteaga y Serna, op. cit., 1980.

85 Se ha vinculado su emplazamiento en un promontorio costero en las inmediaciones de la desembocadura del río Segura con los modelos clásicos defendidos para los enclaves fenicios del Occidente Mediterráneo; vid. Aubet, op. cit., 1994; González Prats, op. cit., 2000; Arteaga y Serna, op. cit., 1980. 
sacra o templo, cuya existencia ha sido justificada pro al existencia de una concentración de estelas-betilo de tipo fenicio reutilizadas en las construcciones de fases posteriores; y una segunda fase Reciente, en la cual el enclave se convierte en una ciudad portuaria con potentes murallas, configurándose en esta área litoral un complejo urbano de tipo oriental incrementado con la existencia de un nuevo santuario dedicado a Astarté en el Castillo de Guardamar, área cuyo uso sacro perviviría hasta epoca iberica. Este entorno costero se complementaría con una presencia fenicia más activa en su territorio circundante con el establecimiento de un barrio artesano en el principal poblado indígena PNII, vinculado con el topónimo de Herna, citado por las fuentes clásicas ${ }^{86}$.

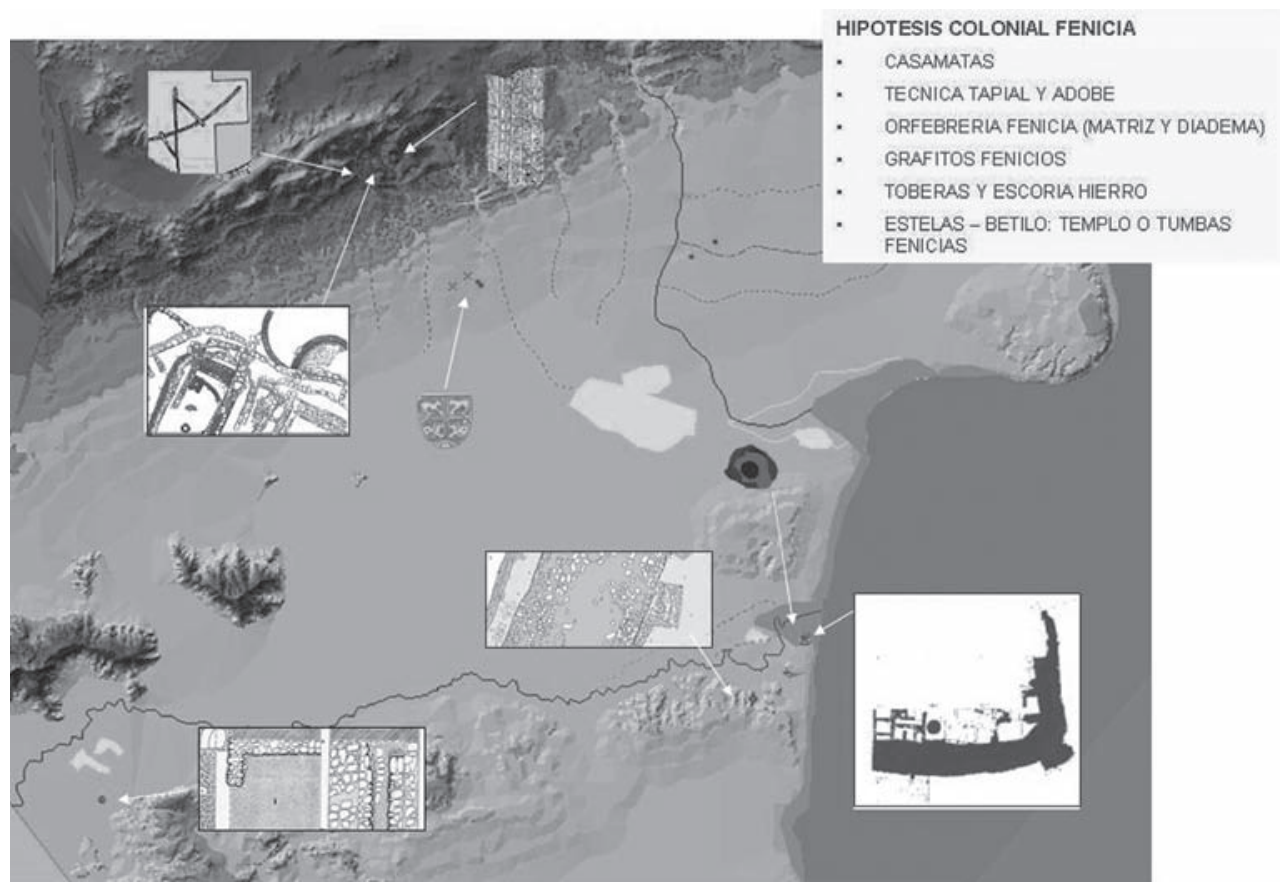

Figura 3. Elementos de la hipótesis colonial fenicia (a partir de VV.AA).

\subsection{El modelo comercial orientalizante de la VBS}

Desde el Bronce Final se detecta la existencia de una reestructuración del poblamiento indígena hacia áreas costeras que desarrollaría una estructura comercial dada la intensidad de contactos e intercambios de productos con otras áreas peninsulares,

86 González Prats, op. cit., 1990. 
sobre todo al quedar incluida la región en los circuitos de intercambio de metales y productos entre el Mediterráneo y el Atlántico, gracias a la existencia de redes de navegación de cabotaje, que determinan una estructuración del poblamiento que prefiere el asentamiento en áreas prelitorales y en zonas de buena comunicación en valles o vías de comunicación con los valles a través de los ríos que hace eclosionar un nuevo modelo de poblamiento indigena que tiene a PN y a Saladares como uno de sus enclaves mas destacados ${ }^{87}$.

El modelo distingue tres momentos en esta estructuración comercial orientalizante: uno más antiguo, entre fines VIII- VII a.C., un segundo de fines del s. VII y el s. VI a.C., y un tercero, a partir de mediados del s. VI a.C. ${ }^{88}$

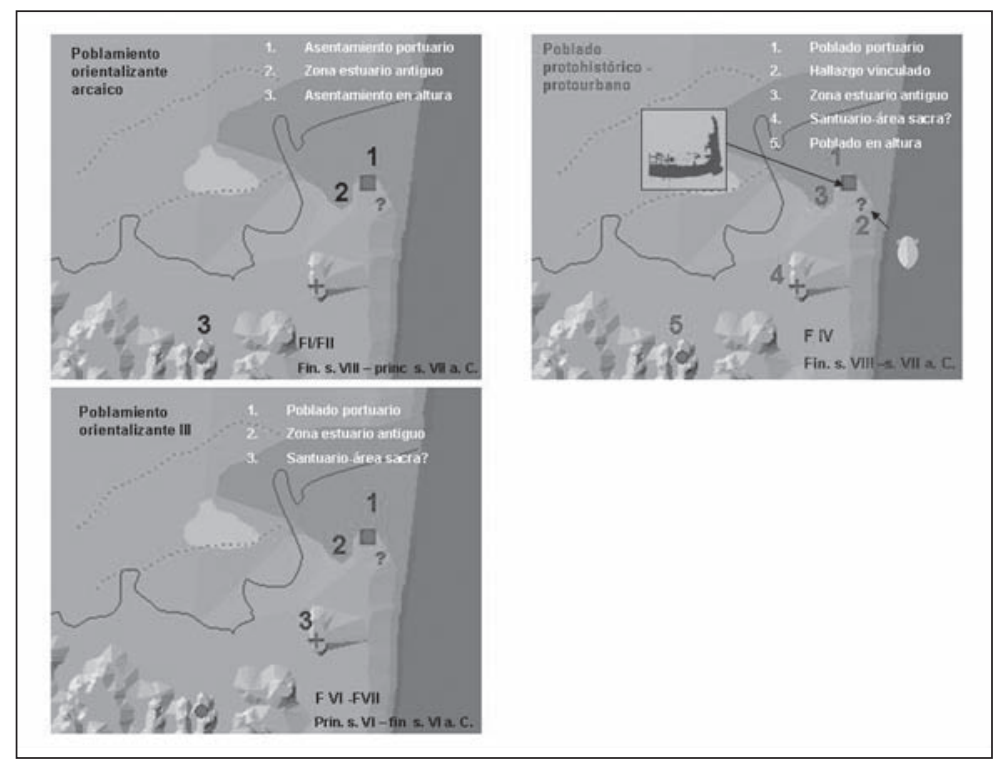

Figura 4. Fases del poblamiento orientalizante en la desembocadura del Segura.

Dado el enorme dinamismo comercial del Mediterráneo Occidental, la estructura de poblamiento indígena se orienta preferentemente a la zona costera, en el entorno del paleoestuario del Segura en Guardamar, con nuevos poblados como Fonteta, Cabeço de l'Estany o Castillo de Guardamar, coincidiendo con la llegada de las pri-

87 S. Pernas García, «La problemática definición de los inicios del Bronce Final», Alebus, Revista del museo Arqueológico de Elda (Alicante), original entregado en enero de 2006 y aceptado el mismo mes, publicación en prensa, Elda, 2006.

88 Rouillard et alii, op. cit., 1998. 
meras evidencias materiales fenicias a finales del s. VIII a.C. ${ }^{89}$ Dicha presencia se ha vinculado una segunda expansión colonial o comercial fenicia de la red fenicio-occidental que amplía su área de extensión a nuevas zonas como el Sureste y el Levante Meridional $^{90}$

Esta temprana presencia fenicia en la Fonteta, dentro de un área, la VBS, donde se desarrolla un foco de población local, impulsa enormemente el circuito comercial, desarrollando un proceso de interacción y aculturación muy fuerte: se ampliarán los productos consumidos por las poblaciones indígenas, se incorporarán novedades técnicas como el torno o la producción metalúrgica, la técnica constructiva del barro. Estos fenómenos han sido documentado en el poblado prelitoral de la PN, el cual ejemplifica que en estas redes de intercambio indígenas la presencia directa de fenicios conllevará un intenso y rápido proceso de interacción cultural de mutuo alcance, es decir, de mistificación o hibridación cultural ${ }^{91}$, que explica la existencia de producciones cerámicas hibridas ${ }^{92}$, la adopción de una producción de cerámica gris a torno que reproduce la tipología indígena ${ }^{93}$, o la existencia de tumbas cuyas urnas de incineración son vasijas fenicias a torno ${ }^{94}$.

La estructura comercial de los s. VII y VI a.C. reforzada por el impulso de la presencia fenicia en las costas, se configuraría a través de:

- un núcleo portuario receptor de mercancías exteriores, sobre todo del entorno fenicio-occidental durante el s. VII y paulatinamente con un aumento de las importaciones griegas que a partir de mediados del s. VI a.C. pasarán a ser muy numerosas ${ }^{95}$.

- dos núcleos productores: uno costero metalúrgico (la Fonteta) y uno interior cerámico, en la S. Crevillente, que podría ser la PN, dada la cantidad de ceramicas localizadas de producción local; y en sus proximidades, talleres orfebrería como Canyada Joana

89 Habría que puntualizar que no es una zona deshabitada para las poblaciones del Bronce, ya que se ha documentado un poblamiento indígena de pequeños hábitats en altura durante el Bronce Tardío en los relieves prelitorales muy próximos al estuario del Segura, a una distancia máxima entre 5 y $6 \mathrm{~km}$ de su desembocadura que desarrollarían estrategia económicas diferentes, más centrada en la explotación de la propia vega del río, que las propias de las poblaciones del Bronce Final, de vinculación eminentemente marítima, vid. Rouillard et alii,, op. cit., 1998, pp.51-52.

90 Vives, op. cit., 2005.

91 P. Van Dommelen, «Colonial matters. Material Culture and postcolonial theory in Colonial Situations», C. Tilley, W. Keane, S. Kuechler, M. Rowlands, P. Spyer, Eds., Handbook of material culture, SAGE, London, pp. 104-124.118-119.

92 Vives, op. cit., 2005, pp.

93 F. Sala, «La cerámique grise», en Rouillard et alii, op. cit. 2007, pp. 199-211.

94 Vives, op. cit., 2005, pp.

95 Rouillard et alii, op. cit. 2007. 
- pequeño núcleos agropecuarios que aportan los recursos básicos de subsistencia

- núcleos de control de comunicaciones en la S. de Crevllente, en S. Orihuela y en los cerros cercanos a la desembocadura del Segura

- un núcleo redistribuidor, la PN que distribuye los productos propios y las importaciones a las áreas interiore del Vinalopó, zona secundaria con grandes recursos agropecuarios

\section{El comercio como interacción social y contacto cultural}

¿Qué tipo de economía existió a principios del I milenio a.C. en la Vega Baja del Segura? ¿Cuándo y cómo surge la economía comercial en la zona? ¿Es dada por la presencia fenicia o es preexistente? Estos son algunos de los interrogantes que tratamos de analizar dentro de un proyecto de investigación general, del cual presentamos aquí una primera aproximación.

\subsection{Modelo teórico: la estructuración del comercio en una economía política}

Defendemos que el modelo teórico de estructuración comercial orientalizante de la VBS podría ser englobado dentro del concepto de Economía política, en la cual la motivación básica sería la restricción del acceso a determinados bienes, debido a que este tipo de economía se centra en la producción y distribución controlada de bienes, lo que conlleva la existencia de procesos claros de jerarquización social o de ruptura de la base comunitaria de la sociedad en grupos gentilicios o individuos preponderantes. T. Earle ha sintetizado las principales funciones del Gran Hombre desarrolladas en las sociedades complejas, en las cuales existe una preeminencia social de un grupo minoritario entre el que destaca una figura principal ${ }^{96}$.

96 Earle destaca varios elementos para definir la figura del Gran Jefe: representa al grupo; su existencia va unida al desarrollo de una economía compleja de grandes inversiones de capital, de una división del trabajo elaborada por tanto existencia de especialistas, grandes obras como estructuras defensivas, etc.; realiza un ciclo ritual que sanciona su función gestora para facilitar y coordinar el bienestar de la comunidad; tiene almacenes mayores que el resto e invierte en ellos mediante el desarrollo de relaciones de clientelismo; se le entregan bienes por sus favores futuros; el jefe redistribuye su riqueza a través de festines y actos generosos; es el promotor de las grandes ceremonias interregionales desarrolladas en momentos destacados del calendario anual y estacional, que son utilizadas para mostrar ostentación, competir por el prestigio del grupo y del jefe frente a otros; provee a la comunidad en caso de carestía o necesidad; desarrolla un intercambio de dones por productos necesarios a nivel interno, y a nivel externo de don-contradon con otros jefes para afianzar alianzas y pactos cooperación, abastecimiento o colaboración puntual, vid. Earle, op. cit., 2005. 
No obstante, para que este binomio comercio-intercambio= jerarquización social sea fructífero, los estudios antropológicos señalan dos precondiciones:

- El desarrollo de estrategias de intensificación económica ${ }^{101}$;

- El desarrollo de estrategias de control restringido sobre bienes y recursos por parte de los dirigentes para obtener un control restringido a los bienes y recursos

Existe una gran controversia de cara a interpretar el intercambio entre fenicios e indígenas, como desigual o no. Para unos es equiparado, ya que señalan que dentro de cada código de valores, indígena o fenicio, sus necesidades son satisfechas de manera satisfactoria durante el intercambio ${ }^{102}$. Para otros, no, ya que el intercambio realizado por los fenicios supone un beneficio de gran valor de cambio, redistribuido entre las élites indígenas, y menor de coste, al ser objetos de menor valor, a modo de baratijas, tal y como describían las fuentes ${ }^{103}$.

\subsubsection{Análisis arqueológico del intercambio en una economía política}

Si este es el modelo teórico aplicado a las poblaciones del Bronce Final peninsulares que entran en contacto con los fenicios a partir de s. VIII a.C., ¿cómo puede ser estudiado el intercambio entre «fenicios» e «indígenas» dentro una economía política que denota la existencia de una incipiente jerarquización social local? ¿Es posible analizar la incidencia del factor orientalizante en la configuración de estas élites? ¿Qué tipo de indicadores podríamos estudiar a nivel arqueológico para intentar describir estas estructuras comerciales?

Superando la pretendida necesidad de distinción de dos comunidades diferenciadas, los fenicios y los indígenas, se debería partir de los datos del registro arqueológico, principalmente referidos a la detección de colecciones de materiales cerámicos, metálicos o de otro tipo, como principales indicios que nos hablan del contacto con otras regiones peninsulares y mediterráneas. Reconstruyendo o explicando los contextos arqueológicos de aparición de los registros en el panorama regional, quizá podamos profundizar en la determinación del tipo de estructura comercial local, sin necesidad de trasplantar modelos nacidos de otras casuísticas.

101 Es decir, que exista excedente productivo y que sea destinado a la inversión en infraestructuras o a la creación de sistemas compensatorios o redistributivos de esa acumulación, necesidades que denoten la aparición de figuras organizativas y coordinadoras en la comunidad facetas que necesitan de estrategias organizativas y de la existencia de un agente coordinador, Johnson y Earle, op. cit. 2003.

102 Vives, op. cit. 2005

103 Wagner, op. cit., 2005. 
Hemos analizado los yacimientos en los que se evidencian materiales arqueológicos que denotan intercambio en la VBS de cronología orientalizante ${ }^{104}$. Intentaremos analizar si el registro arqueológico nos permite indagar acerca del valor social dado a los diferentes bienes de intercambio, a fin de poder dirimir si existen argumentos para poder aplicar los modelos antropológicos de formas de intercambio defendidos para una economía política.

Con ello podríamos aportar argumentos arqueológicos para defender una ruptura de la base social de las comunidades indígenas; establecer la tipología funcional de los diferentes yacimientos en clave económica-comercial (centros de producción, redistribución, etc.), y tras el análisis comparativo de los materiales documentados en cada yacimiento, estipular, los flujos de dicho intercambio.

\section{- Los tipos de objetos intercambiados: objetos de otra procedencia o de pro- ducción local}

En el total de yacimientos analizados, un total de $22^{105}$, se ha documentado la existencia de una variada tipología de materiales orientalizantes.

Vamos a tomar como ejemplo de análisis, la cerámica a torno, que está presente en todos los casos con una diferencial presencia. En todos los yacimientos en los que se detecta cerámica a torno orientalizante, sólo un $27 \%$ tiene cerámica de tipo fenicio occidental, de la zona del sur peninsular, principalmente la costa malagueña, mientras que el $73 \%$ presenta cerámica de producción local de tipo fenicio u orientalizante. Entre la cerámica importada, se distinguen claramente tres focos de procedencia principales: las producciones fenicias-occidentales del sur meridional; las producciones fenicias de la zona de Cartago, para las que se ha propuesto que arribarían a través del intercambio con Ibiza ${ }^{106}$, y por último las producciones centro- mediterráneas, principalmente griegas. En un primer análisis sin entrar a valorar la mayor o menor presencia de cada tipo de cerámica en cada yacimiento, la comparación del porcentaje de presencia/ausencia respecto al total de yacimientos, es ya indicativo de tendencias comerciales:

104 Pernas García, op. cit., 2005, pp. Catalogo Bajo Segura y Baix Vinalopo.

105 Los Saladares, Laderas de S. Miguel en Orihuela; La Fonteta, Castillo de Guardamar, Cabeço de l'Estany y El Molar en Guardamar; El Oral, San Fulgencio; Ladera del Castillo Sta Bárbara, Cox en el Bajo Segura. En la comarca del Baix Vinalopó, Penya Negra, Les Moreres, El Botx, Camí de Catral, El Castellar, Les Barricaes, Cantal de la Campana, Coto Memoria, Corral Oeste del Castellar, Pic de les Moreres, Penya Fongua, Canyada Joana en Crevillente; L'Alcudia, Caramoro II y Hacienda Botella en Elx.

106 González Prats, op. cit, 2000. 


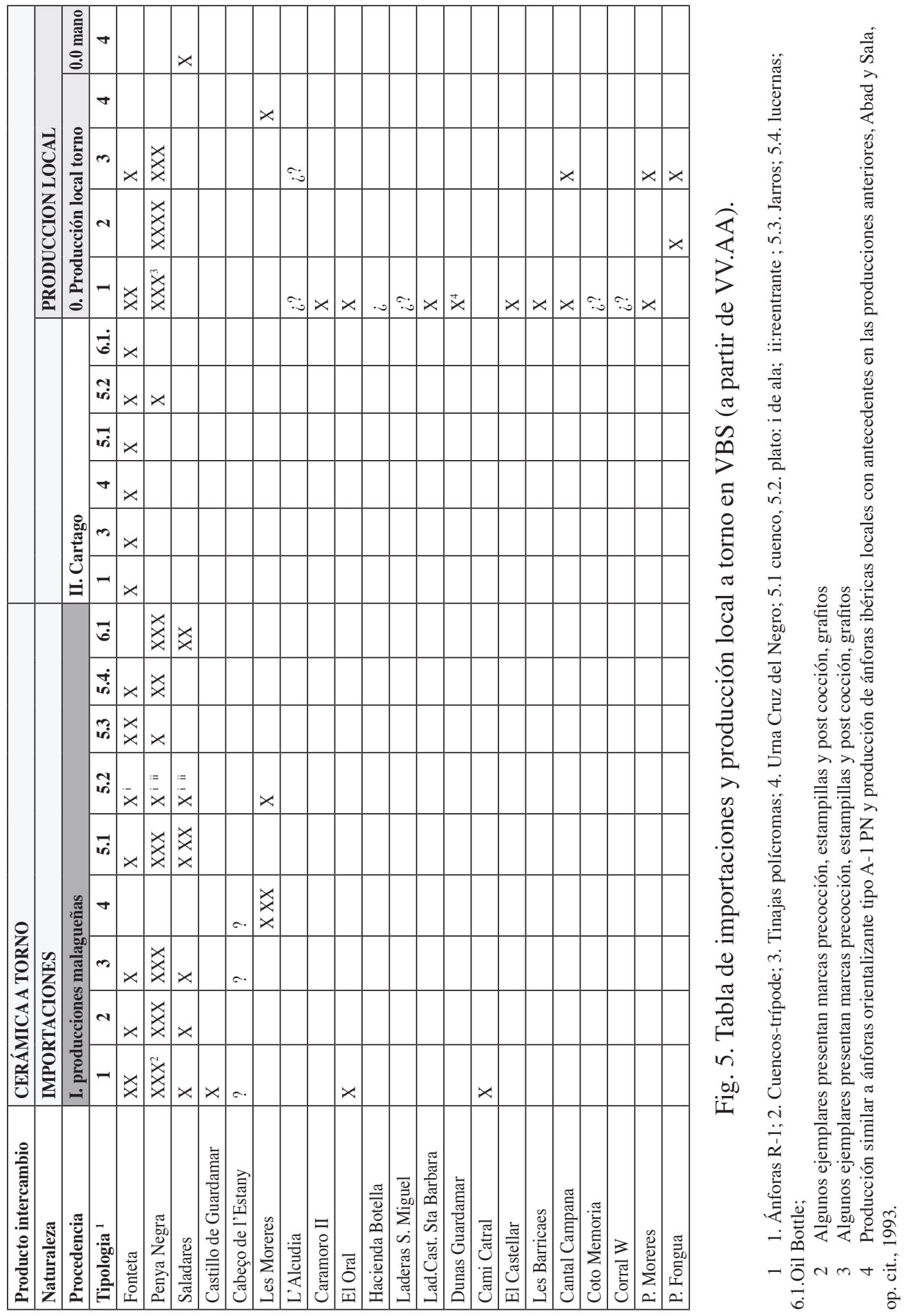




\begin{tabular}{|l|c|c|c|c|c|c|c|c|}
\hline Producto intercambio & \multicolumn{6}{l|}{ CERÁMICA A TORNO } \\
\hline Naturaleza & \multicolumn{6}{l|}{ IMPORTACIONES } & \multicolumn{2}{l|}{ LCALES } \\
\hline Procedencia & \multicolumn{6}{|l|}{ III. Importaciones centro-mediterráneas } & \multicolumn{2}{|c|}{} \\
\hline Tipologia $^{1}$ & $\mathbf{1}^{\mathbf{2}}$ & $\mathbf{2}^{\mathbf{3}}$ & $\mathbf{3}^{\mathbf{4}}$ & $\mathbf{4}^{\mathbf{5}}$ & $\mathbf{5}^{\mathbf{6}}$ & $\mathbf{6}^{7}$ & $\mathbf{1}^{\mathbf{8}}$ & $\mathbf{2}^{\mathbf{9}}$ \\
\hline Fonteta & $\mathrm{X}$ & & $\mathrm{X}$ & $\mathrm{X}$ & & & $\mathrm{X}$ & \\
\hline Penya Negra & & & & & & & & $\mathrm{X}$ \\
\hline El Oral & $\mathrm{X}$ & & $\mathrm{X}$ & & $\mathrm{X}$ & & & \\
\hline EL Molar & & & & & & $\mathrm{X}$ & & \\
\hline
\end{tabular}

Figura 6 .Tabla de importaciones de origen griego en VBS (a partir de VV.AA)

1 1. Ánforas R-1; 2. Cuencos-trípode; 3. Tinajas polícromas; 4. Urna Cruz del Negro; 5.1 cuenco, 5.2. plato: i de ala; ii:reentrante ; 5.3. Jarros; 5.4. lucernas; 6.1.Oil Bottle;

2 Fonteta: Fines s. VIII a.C.: cerámica corintia tipo Thapsos y tipo Aetos 666, González Prats, op. cit. 2000, pp. 55; mediados de s. VII a.C.: cerámica protocorintia tipo Kotylai y ánfora corintia. El Oral: Fines s. VI a.C. - principios s. V a.C.: ánforas corintias de borde biselado tipo B corintio y ánforas massaliotas

3 Principios s. VI a.C.: cerámica ática a la brosse, procedente de Ibiza; Primera mitad s. VI a.C.: cerámica copa jonia ática, García Martín, op. cit, 2000, pp. 211; segunda mitad s. VI a.C.: copas jonias tipo B2, García Martín, op. cit., 2000, pp. 213-215.

4 Primera mitad s. VI a.C.: La Fonteta, cerámica samia, quiota; García Martín, op. cit., 2000, pp. 213-215. El Oral, ánfora quiota Abad y Sala, op. cit. 1993.

5 Primera mitad s. VI a.C.: ánforas etruscas arcaicas, García Martín, op. cit., 2000, pp. 215.

6 Fines del s. VI a.C.: cerámica de barniz negro tipo copa de pie alto Tipo $\mathrm{C}$ de Bloesch.

7 Fines s. VI - principios s. V a.C.: cerámica de figuras negras, A. Peña, La Necrópolis del Molar, San Fulgencio, Alicante, 2003, Tabla 11, pp. 116.

8 Imitación fenicia de cerámica de tipo eubeo, skyphos, García Martín, op. cit., 2000, pp. 211.

9 Imitación local de cerámica griega tipo vaso escifoide y píxide stamnoide, A.González Prats, «El componente tipológico griego en el ambiente cerámico de PN II (675 - 550 a.C.)», Lucentum, I, 1982.

\section{FALTA FIGURA 7}

Figura7. Porcentajes de presencia de la cerámica a torno en VBS durante el s. VII a.C. 
Durante el s. VII a.C. mayoritariamente, predomina la producción local a torno, un $57 \%$, cuyo foco de mayor aparición es el área de la Sierra de Crevillente, destacando la ingente cantidad de producción local o regional documentada en este yacimiento. En cuanto a las importaciones, existe una mayor difusión de los tipos cerámicos fenicios provenientes de la costa malagueña, un $23 \%$, que se documentan en los enclaves principales de las tres áreas de la VBS: en la Fonteta, en la desembocadura del río y en sus inmediaciones, Castillo de Guardamar y Cabeço de l'Estany; en Saladares, en la salida sur del valle; en Penya Negra en el área de la Sierra de Crevillente, que enlaza con el Valle del Vinalopó. Mientras, las otras importaciones no superan el $20 \%$ conjuntamente, y su área de distribución se limita a dos yacimientos, uno costero, la Fonteta y otro, prelitoral, la Penya Negra.

En el yacimiento de PN, tanto el variado y numeroso repertorio cerámico localizado, de producción exterior (principalmente zona malagueña y en menor medida de Cartago) y de producción local, representado principalmente por las ánforas A-1 de producción local, como variada tipología de objetos orientalizante metálicos en el horizonte PNII, ha permitido plantear la naturaleza del enclave como centro redistribuidor, almacenador de productos y redistribuidor en su propio entorno y el intercambio con otras áreas como el Valle del Vinalopó ${ }^{107}$. Además, la presencia del Tesorillo o la ocultación de la Penya Negra, formada por objetos de difícil documentación en otros yacimientos del entorno, ya sea por sus características formales, técnicas o el tipo de material, oro, ha servido para aducir la existencia de los primeros signos de diferenciación social o de existencia de algún tipo de jefatura, vinculándose también con la documentación de una diferenciación del tipo de ajuares en su necrópolis de Les Moreres, en la cual algunos pocos casos, se reutilizan ánforas fenicias como urnas cinerarias, y sobre todo existe una diferenciación entre ajuares ${ }^{108}$

\section{- El consumo de productos: una propuesta a partir del continente}

En este artículo hemos seleccionado para su análisis una clase de producción documentada con gran profusión en todos los yacimientos, la cerámica a torno de almacenamiento y transporte, por ello sólo vamos a comentar brevemente algunos aspectos sobre el consumo de productos que serían susceptibles de ser transportados en este tipo de recipientes.

Sobre la determinación de los tipos de productos intercambiados entre los diferentes poblados, existen diferentes propuestas: Arteaga y Serna en 1980 siguiendo los parámetros culturalistas propios de la época, proponía que las «importaciones reflejan unas relaciones incidentes, un comercio de penetración que se fundamenta en la introducción de contenidos exóticos (aceite, vino, etc.) y no en los propios re-

107 González Prats, op. cit., 1992; Moratalla, op. cit., 2004.

108 A. González Prats, La necrópolis de les Moreres, Crevillente, Anejos de Lucentum, 2002. 


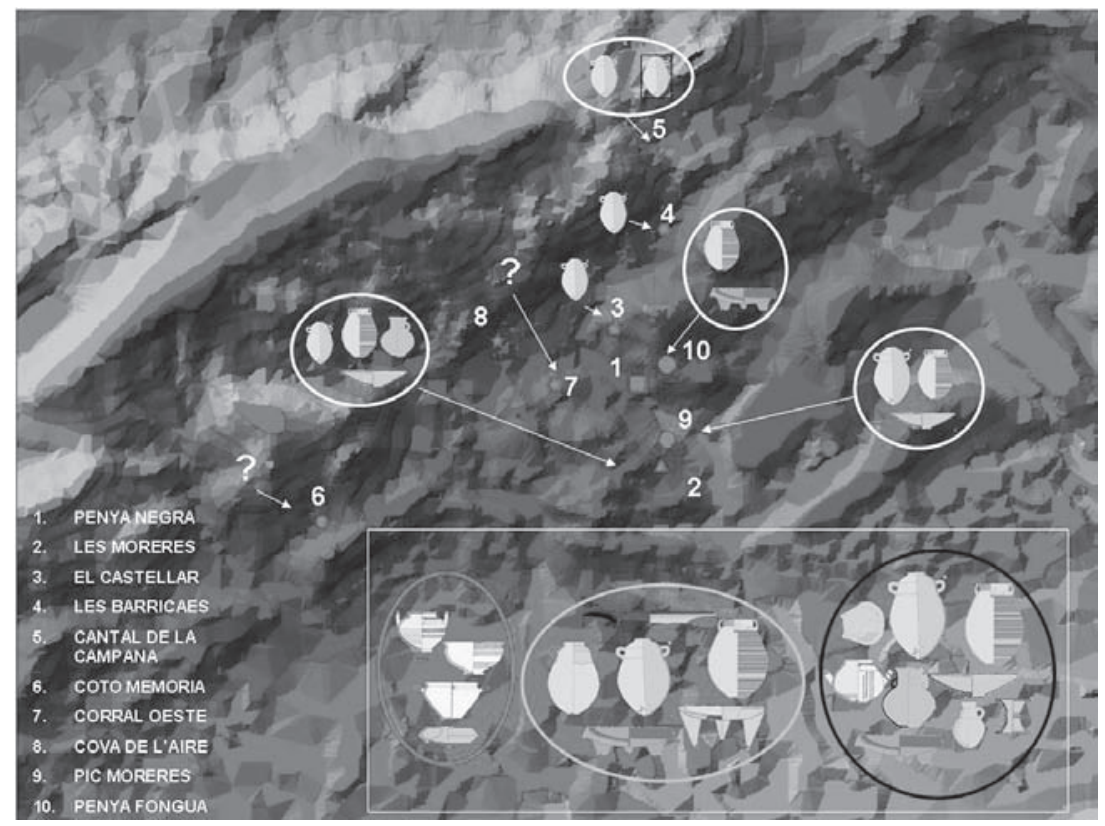

Fig. 8. Distribución cerámica orientalizante en la Sierra de Crevillente. El recuadro pertenece al repertorio de PN.

cipientes» por parte de los fenicios ${ }^{109}$. A cambio, se ha aducido que los «indígenas» les abastecían de metales, según propuesta de A. González Prats en 1992, dentro de «un momento marcado por la búsqueda de metales especialmente el estaño del que era deficitaria la cuenca oriental del Mediterráneo» ${ }^{110}$. Estudios de «site cachement analysis» han destacado la importancia de los recursos agrícolas de la zona del VBS así como la posibilidad de una explotación salina en la zona del entorno de los Saladares ${ }^{111}$ y del Valle del Vinalopó ${ }^{112}$.

No obstante, la inexistencia de analíticas de componentes en los recipientes cerámicos, a en conjuntos de fecha orientalizante en la VBS, no permiten determinar con seguridad que transportaban los recipientes anfóricos, aunque se suele aducir una triple funcionalidad: trasporte de vino, de cereal y de productos en salazón.

109 Arteaga y Serna, «Las primeras fases del poblado de los Saladares», Ampurias, t. 41-42, 1980, pp. 65-137.

110 A. Gonzalez Prats, op. cit, 1982.

111 Grau y Moratalla, op. cit, 2001; Moratalla, 2004.

112 A. Mederos, «La metamorfosis de Villena. Comercio de oro, estaño y sal durante el Bronce Final I entre el Atlántico y el Mediterráneo (1625-1300 a.C.)», T.P. 52, nº 2, Madrid, 1999, pp. 1-22.; Poveda, op. cit. 1994; 2000; Pernas García, op. cit 2006. 
Si analizamos la distribución de tipos cerámicos, comprobamos como existe una restricción en el consumo o consumo diferencial según yacimientos. Existe una dispersión homogénea de algunos tipos, principalmente cerámica de almacenamiento, ánforas, presentes en la mayoría de los yacimientos, con mayor o menos intensidad, seguidas de las tinajas. No obstante, se documenta una mayor variabilidad tipológica con una gradación diferenciada:

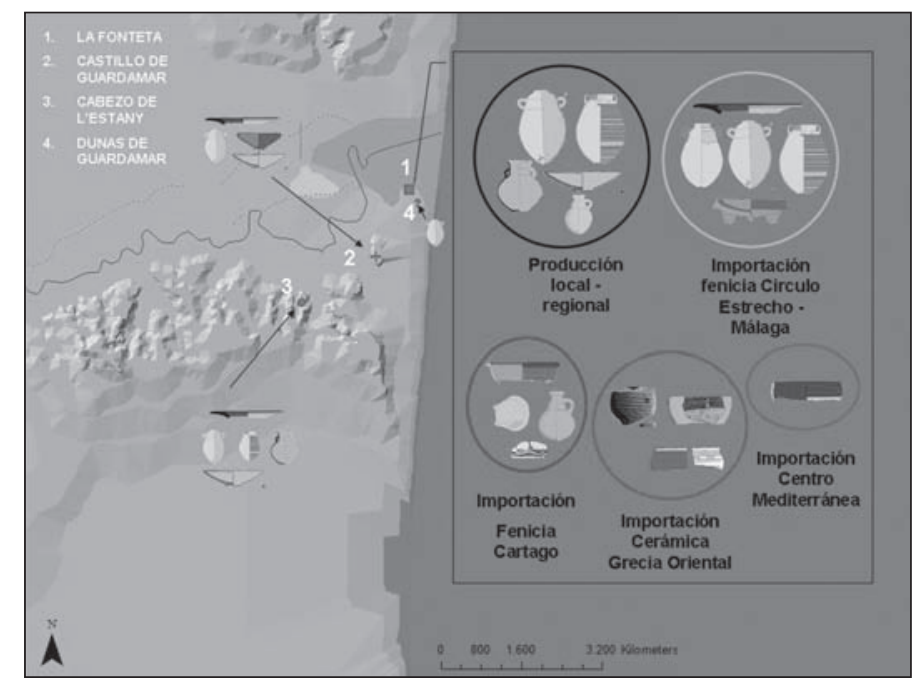

Figura 9. Distribución por tipos cerámicos en la zona de la paleodesembocadura del río Segura.

1) Núcleos que poseen numeroso y variado repertorio de cerámica importada a torno, de varias procedencias: Fonteta, Penya Negra, existiendo una gradación y diferenciación entre los dos núcleos. Es decir, al enclave costero llega una mayor variabilidad de tipos a lo largo de toda la secuencia.

2) Núcleos que poseen menor variedad en el repertorio cerámico importado a torno, Saladares, así como una producción local de cerámica a torno gris orientalizante.

3) Núcleos que poseen algunos tipos determinados de cerámica a torno importada: cerámica de engobe rojo, ánforas R-1 y tinajas, y en determinados casos también cerámica gris orientalizante de producción local como el Castillo de Guardamar.

4) Núcleos que presentan principalmente cerámica de almacenamiento, ánforas y tinajas, y en un caso, un fragmento de cuenco-trípode.

5) Núcleos que sólo presentan algunos ejemplares o fragmentos de ánfora A-1 de producción local. 

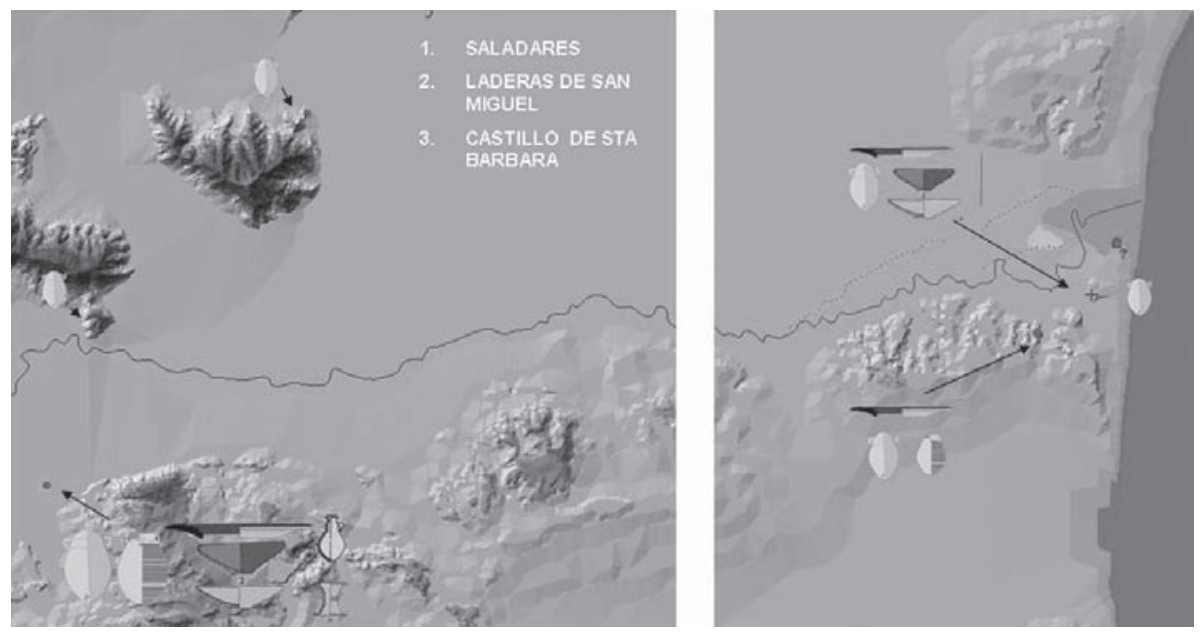

Figura 10. Distribución por tipos en la VBS: 1. Inicio de la vega o valle del Segura; 2. Paleoestuario o desembocadura del río Segura.

Así pues, estas diferenciaciones pueden hacer plantear algunas hipótesis: el acceso o restricción de determinados productos es diferente según zonas, con una diferencia clara entre costa e interior, pero también tiene que ver con el tipo de yacimiento, ya que los yacimientos más grandes y con más rico registro documentado son los que acaparan las importaciones de productos exteriores, y además tienen mayor presencia de cerámica de producción a torno orientalizante. Destacar además que en los núcleos intermedios (tipo 3), se documenta junto a estas importaciones la presencia de producción de cerámica gris a torno local.

Además, si partimos de la propuesta realizada recientemente que vincula la presencia de ánforas A-1, tanto de producción local como importada, con la presencia de algún ejemplar de cuenco-trípode, con una evidencia del consumo de vino aderezado, costumbre claramente oriental ${ }^{113}$, coincidencia que localizamos en cuatro casos, tres núcleos de tipo 1 y 2, y un último, de tipo 3, estaríamos ante un indicio del grado de integración cultural y comercial de la zona, que tiene asimilado y reproduce gustos o hábitos vinculados al mundo mediterráneo. Además la escasez del hallazgo de esta combinación, podría además estarnos marcando un uso restringido de dicha práctica social, concentrada en los tres poblados cada de cada territorio. Este reparto no homogéneo, sino concentrado en pocos sitio y disperso entre sí, nos evidencia quizás un valor de estatus respecto a este producto.

113 Vives, op. cit., 2005. 
Así mismo podemos señalar que del total de yacimientos existen varios tipos cerámicos que reproducen esta tendencia hacia una dispersión no homogénea sino concentrada: es el caso de la cerámica de barniz rojo, de los carretes, y de las botellas tipo oil bottle.

Como ya hemos visto anteriormente a esta diferenciación se añadiría la de la procedencia de los tipos cerámicos. Tipos cerámicos de Cartago sólo llegan a la Fonteta, y en Penya Negra está representado por un plato de engobe rojo de mediados del s. VII a.C. La cerámica de origen griego sigue el mismo patrón, se concentra desde fines del s. VIII a.C. en la Fonteta, hasta la segunda mitad del s. VI a.C. que comienza a documentarse en yacimientos ex novo como El Oral y su necrópolis, El Molar.

Así pues existen indicios arqueológicos de una enorme integración entre poblados, de un intercambio que da un acceso restringido a determinados hábitats, que hace que esta área meridional, goce de una gran representatividad de tipos cerámicos orientalizantes, variedad y dispersión que no se da en regiones septentrionales, aunque podemos señalar que este acceso se restringiría a algunos puntos o poblados con importante en las redes de comunicación o contacto, ya que sólo en ellos se localiza esta variada tipología orientalizante. Sobre las formas de intercambio desarrolladas en estos momentos, hemos visto que existen indicios para pensar que podría desarrollarse un modelo de intercambio con valor de status o restringido a algunos grupos gentilicios, ya que: como hemos dicho el acceso es restringido a unos poblados determinados, principalmente la Fonteta y Penya Negra, y en el caso de la PN, existen indicios de diferenciación social en los ajuares funerarios y en la existencia de ocultaciones. No obstante sería necesario realizar un estudio microespacial para determinar un posible patrón de aparición de los bienes de prestigio en cada ámbito doméstico, para poder argumentar si existe una diferenciación de casas, espacios en el poblado clara, siendo el único indicio, la concentración de materiales en las secuencias estratigráficas de algunos sectores del poblado.

\subsubsection{La estructura comercial}

La estructura comercial como definición es la organización física y mental del intercambio de bienes, que incluiría por un lado, los centros reproducción, distribución, centralización o redistribución; las rutas de intercambio, tanto terrestres como marítimas o fluviales; los sistemas de intercambio (los valores de intercambio y las firmas en las que se materializa); la categorización de los bienes (los productos intercambiados), los agentes del intercambio (personas que quedan involucradas en estas actividades). 
A nivel arqueológico las estructuras comerciales en un territorio pueden estudiarse, comprobando si existen las variables principales de cualquier estructura comercial: centros productores y/o centros de redistribución, puntos de control, etc. Es decir, detectar yacimientos que posean toda o parte de la cadena de producción de un bien; localizar en el territorio la existencia de recursos necesarios para la producción y el grado de accesibilidad ${ }^{114}$.

Dentro de las estructuras comerciales de cualquier modelo de análisis se distinguen por un lado los centros productivos, los centros redistribuidores y los centros de control de comunicaciones. No obstante, dentro de los centros productivos, se debe establecer una diferenciación entre aquellos referidos a una producción artesanal, de carácter eminentemente redistributivo o comercial, y los centros o enclaves destinados a producir bienes subsistenciales, principalmente alimentarios o agrícolas.

\section{- los centros productores I: los centros artesanales}

Respecto a la existencia de centros productivos en época orientalizante en la VBS se han citado varios centros por la investigación: la Fonteta como centro productor metalúrgico, la PN como centro productor cerámico y en sus inmediaciones un taller de orfebrería orientalizante.

En referencia a la Fonteta, con las evidencias arqueológicas que disponemos actualmente, no existe duda de la naturaleza de dicho enclave como centro de producción metalúrgica, dada la existencia en varias de sus fases de evidencias de bienes de producción como toberas, hornos y residuos como escorias de hierro y litergirio ${ }^{115}$,

114 L. García Sanjuán, Introducción al reconocimiento y análisis arqueológico del territorio, Ariel, 2005.

115 En fases más antiguas FI y FII, s. VIII - principios VII a.C. se documenta una mayor actividad, con la existencia de un taller metalúrgico con rica presencia de bienes de producción: niveles superpuestos de hornos, toberas, moldes de hachas o escoplos de bronce de fundición así como numerosas escorias polimetalúrgicas, que muestran una incipiente metalurgia del bronce y del hierro, o la copelación de plata (tortas de litargirio y gotas de plomo), así como una variada tipología de toberas que muestran la incorporación de una nueva tecnología del metal, no conocida en los registros metalúrgicos de la zona. vid. A. González Prats y M. Renzi, 2003, ElHombre y los metales, en El hombre fenicio, pp. 157; M. Renzi, RENZI, M., Estudio tipológico y funcional de las toberas del yacimiento de la Fonteta (Guardamar del Segura, Alicante), T P,64, No 1, Enero-Junio 2007, pp. 165-177.; mientras en la fase FIII, desciende la actividad, documentándose una zona siderúrgica con cinco dependencias en las que se evidencias una división funcional del espacio, unas áreas para el triturado, dada la existencia de un empedrado con varios machacadores de mineral in situ, y otras para la fundición del mineral, con evidencia de moldes, tortas de metal, toberas vitrificadas in situ junto a grandes vasijas destinadas, según se ha argumentado a contener agua; y otra con evidencias de producción de bronce, en la cual además de toberas y escorias, se han documentado moldes de hachas de apéndices laterales GP y Ruiz Segura, 1997; GP, GP 2005, GP y Renzi, op.cit., 2003. 
actividad metalúrgica presente a lo largo de toda la secuencia, destacando la existencia de potentes niveles de escombreras metalúrgicas en algunas de estas fases.

Otra cuestión es la discusión existente sobre si esta producción refleja la presencia de poblaciones fenicias establecidas ya que la metalurgia «es una de les activitats bàsiques de la instal.lació fenícia que han pogut ser fermament establertes» ${ }^{116}$, o si en cambio no es posible argumentar una distinción clara entre fenicios o indígenas dada la intensidad de los contactos e interacciones ${ }^{117}$. Además, la aceptación de los argumentos arqueológicos para defender que se trata de un centro productor metalúrgico con un papel destacado dentro del contexto regional durante la primera mitad del s. VII a.C. no es unánime. Ante la falta de la publicación de un estudio global de todas las evidencias de actividad metalúrgicas localizadas en el yacimiento que nos permita medir el alcance de estas producciones, no existe un consenso en su interpretación por parte de los equipos de investigadores que analizan esta cuestión. Así las propuestas de González Prats, hablan de una producción metalúrgica enfocada al comercio e intercambio exterior, dada la existencia de la rica presencia de bienes de producción metalúrgica, mientras las evidencia documentadas por el otro equipo de P. Rouillard, apuntan a que, en el área estudiada se trata de una producción de autoconsumo, destinada ala producción o comercialización local de objetos de adorno personal y objetos para el autoconsumo como cuchillos de hierro, puntas de tipo Macalón, entre otros ${ }^{118}$. Si comparamos el rico registro localizado en el área próxima a la antigua línea de playa, con el más limitado registro localizado en el sector excavado por e equipo de Rouillard, quizá esta divergencia podría deberse a una diferenciación funcional de los diferentes sectores del asentamiento, que combinarían una producción de autoconsumo, con otra, centrada en la producción de plata y hierro destinada a una distribución más amplia.

Otro de los enclaves definidos como centros productores es la Penya Negra, en el cual se desarrollaría una importante actividad metalúrgica desde el BF con presencia de una producción de objetos de tipo atlántico en PNI, y en la fase plenamente orientalzante, PNII, una producción de cerámica a torno local con una variada tipología y distribución regional ${ }^{119}$.

Los argumentos arqueológicos para defender la naturaleza de la PN como centro productor cerámico son: la existencia de un variada y cuantiosa tipología cerámica a torno de producción local, tal y como ha demostrado los análisis de pastas y la pre-

116 Gonzalez Prats, op. cit., 2005, pp. 54.

117 Vives, 2005, pp. 174

118 H. Le Meaux y Mª D. Sánchez de Prado, «Le mobilier non céramique», en P. Rouillard, E. Gailledrat et F. Sala, Eds, L'establissement protohistorique de La Fonteta (fin VIII - Fin VI siecle av. J.C., Casa Velzquez Vol. 96, Madrid, 2007, pp. 327.

119 González Prats, op. cit., 1983. 
sencia de marcas de alfarero locales ${ }^{120}$. No obstante, se reconocen algunos problemas de registro como la inexistencia de evidencias de bienes de producción cerámica en el lugar tales como hornos susceptibles de usarse con fines industriales de producción cerámica, evidencias de pruebas de cocción o ejemplares con defectos, áreas de desecho de fabricación como testares, la determinación de pastas de procedencia local son argumentos que señala la existencia de una composición mineralógica coincidente con la composición del terreno no solo en la Sierra de Crevillente sino a nivel regional, no pudiéndose argumentar por esta línea nada más que existía en el entorno de los yacimientos de VBS un aprovisionamiento factible de recursos arcillosos, con lo cual la documentación de producción local en otros enclaves cercanos como Fonteta, Cabeçó de l'Estany, etc, en los que tampoco se cuenta con evidencia de bienes de producción, plantea como mejor solución intermedia por el momento, asumir que se trata de una producción regional como mucho comarcal circunscrita al VBS, pudiéndose vincular o no con la $\mathrm{PN}^{121}$. En cualquier caso se acepta la existencia de una importante producción regional de tipo fenicio diferenciada respecto al resto de áreas de producción del Mediterráneo ${ }^{122}$.

Al igual que el caso de la Fonteta, tampoco existe una unanimidad en la interpretación de dicho centro como productor cerámico indígena orientalizante, sobre todo porque se aplica habitualmente la misma lectura étnica binaria que pretende distinguir arqueológicamente a fenicios e indígenas. Se ha argumentado que la presencia de cerámicas de tipo fenicio con grafitos fenicios en el enclave, es una muestra de la existencia de población fenicia en el poblado, proponiendo la existencia de un barrio artesanal de población fenicia en el enclave que desarrollaria la producción cerámica de tipo fenicio local, aunque existen numerosos detractores de esta propuesta ${ }^{123}$.

Por ultimo el tercer centro productor propuesto, es la existencia de un taller de orfebrería en VBS, cuya existencia se basa en la localización en superficie de varias matrices de bronce que muestran un programa iconográfico plenamente orientalizante, los llamados Bronces de Candela en algunos enclave en el glacis crevillentino ${ }^{124}$

El estudio estilístico y formal de estos ejemplares ha podido vincularse con objetos aparecidos en los enclaves de PN, en la diadema de oro del tesorillo y en el col-

120 González y Pinna, op. cit. 1983.

121 Vives, op. cit., 2005.

122 RAMON J., Las ánforas fenicio púnicas del Mediterráneo Central y Occidental, Barcelona, 1995.

123 Vives, op. cit. 2005; Rouillard et alii, 1998; Moratalla.op. cit. 2004..

124 González Prats, op. cit, 1986;»Dos Bronces fenicios de la Colección Candela: Aportación al conocimiento de la orfebrería e iconografía orientalizante de la Península Ibérica», en Tartessos. Arqueología Protohistórica del Bajo Guadalquivir, Barcelona, 1989, pp. 411-430; Pernas García, op. cit., 2005: 247-250. 
gante de la Fonteta ${ }^{125}$. Estas evidencias han servido para apuntar la existencia en las inmediaciones del poblado de la PN, de un posible taller de orfebrería orientalizante. Su localización geográfica no obstante sigue siendo dificultosa, ya que el ejemplar de Cami de Catral se ha vinculado con un contexto funerario, mientras que Canyada Joana es un hallazgo superficial. Por tanto, la inexistencia en PN de matrices o evidencias de producción y no sólo de objetos terminados como los del tesorillo, no permiten aclarar la localización geográfica de este taller. Todas estas evidencias han sido fechadas en torno al s. VI a.C., y son un claro precedente de otros ejemplos localizados en la región en contextos más tardíos, ya plenamente ibéricos, como las matrices de Cabezo Lucero ${ }^{126}$.

\section{- los centros productores II: asentamientos agrarios}

Estos centros, se describen a partir de la dispersión cerámica en superficie, y en algunos casos por la existencia de niveles estratigráficos, caso de Los Saladares, la Alcudia, Hacienda Botella. Estos tres últimos casos han sido documentados principalmente mediante excavación, gracias por un lado, a la importante tradición investigadora y a los numerosos proyectos de investigación que se vienen desarrollando en la zona en las últimas décadas; y en otros, a la labor de la arqueología de urgencia. El yacimiento más emblemático dentro de esta categoría es sin duda, Los Saladares de Orihuela, el cual ha sido destacado habitualmente por su función geoestratégica de control de las vías de comunicación de salida hacia el tramo medio del valle, aunque recientemente se ha añadido otras, de índole económica, como la explotación salina, dada su proximidad al entorno de Los Saladares de Arneva, al sur del curso del Segura y agrícola, dada su proximidad a la vega del río, de alta capacidad agrícola ${ }^{127}$. Estudios de territorio recientes, han planteado una extensión media para estos enclaves que oscila entre los 0,3 ha de los Saladares a 1 ha de la Alcudia, dimensión última, propuesta recientemente para delimitar la extensión de época prehistórica, ya que en principio la escasez del registro recuperado, principalmente cerámica de tipo fenicio, no parece que pueda corroborar la equiparación en momentos orientalizantes a las dimensiones del poblado en época Ibérica antigua, en la cual arriba hasta 6 ha $^{128}$.

Si exceptuamos el caso de Saladares, los registros arqueológicos no deparan excesivas evidencias de hábitat en estos poblados, exceptuando la documentación de construcciones de tipo perecedero como fondos de cabaña circulares o vertederos de cro-

125 González Prats y Renzi, op. cit., 2003.

126 H. Uroz, El programa iconográfico religioso de la «Tumba del orfebre» de Cabezo Lucero (Guardamar del Segura, Alicante), Monografías de Arte Ibérico de El Cigarralero, 2006, pp. 166-167.

127 Grau y Moratalla, op. cit. 2001, pp. 189-196.

128 Moratalla, op. cit. 2004. 
nología del Bronce Final, como Hacienda Botella, en las inmediaciones de la Alcudia y que no presenta materiales a torno. Así pues, deberemos partir del análisis conjunto de sus características geoespaciales, así como de sus conjuntos cerámicos a fin de intentar definir una diferenciación funcional. El análisis de sus materiales cerámicos no nos indica una cierta especialización diferenciada de la de los enclaves interpretados hasta el momento como fortines de control estratégico como los que rodean a la PN en la Sierra de Crevillente, dada la homogeneidad y reiteración de los conjuntos localizados, recipientes de almacenamiento, tipo ánfora o tinaja principalmente. En este sentido, sólo el análisis del territorio y espacial puede determinar con más exactitud su funcionalidad como centros productivos, interpretando siempre estas afirmaciones como hipótesis de trabajo ante la ausencia de excavaciones en extensión; la escasez de una muestra representativa de evidencias materiales, la ausencia de evidencias productivas vinculadas con el trabajo agricultura tales como herramientas o aperos y por último la falta de una analítica de contenidos que permitan aseverar que producto almacenaban en estos recipientes. Por tanto debe valorarse cómo su vinculación con la producción agraria a partir del análisis del conjunto cerámico es una hipótesis de trabajo, que interpreta esta presencia de cerámicas de transporte y almacenamiento con función principalmente de almacenaje de grano o productos en salazones. La inexistencia de una línea de investigación generalizada sobre contenidos en el análisis de la cerámica almacenaje y transporte de tipo orientalizante en la VBS, evidencia la complejidad de establecer qué productos almacenaban las ánforas o las tinajas. En este sentido cabe destacar recientes propuestas que proponen la existencia en algunos enclaves de una pauta que asimila la presencia de ánforas fenicias junto con recipientes de tipo cuenco-trópode, vinculada con el consumo de vino ${ }^{129}$.

\section{- puntos de control geoestratégico}

Los puntos de control geoestratégico han sido definidos recientemente como fortines de control sobre el territorio y las vías de comunicación dadas unas características reiterativas: el emplazamiento en relieve de altura diversa, desde emplazamiento en lo alto de destacados cerros hasta la ocupación de pequeñas elevaciones. La pauta la marca la visibilidad que goza cada emplazamiento de las vías de comunicación y el entorno circundante, más que la altura relativa a la que se sitúen ${ }^{130}$.

Se ha defendido que esa funcionalidad específica, defensiva y estratégica, se asocia a la aparición de fortificaciones en dichos enclaves, como el caso de Caramoro II, el Castellar, Cantal de la Campana o Les Barricaes entre otros. E incluso se ha vinculado a episodios de conflicto fruto de la presencia fenicia, que hace que las poblacio-

129 Vives, op. cit, 2005.

130 Pernas García, op. cit., 2005, pp. . 
nes locales respondan con un refuerzo del control sobre el territorio. En este sentido, ha sido interpretado el enclave del Cabeço de l'Estany ${ }^{131}$.

No obstante, el análisis de otras variables como explotación de recursos, la accesibilidad y proximidad a recursos naturales en los entornos de los yacimientos, ha deparado en otras áreas próximas como el Valle del Vinalopó, para época del Bronce Final prefenicio, la muestra de que se trata de enclaves ambivalentes, con una múltiple funcionalidad, tanto geoestratégica como de explotación de recursos de tipo forestal, ganadero e incluso agrícola en algunos $\operatorname{casos}^{132}$.

Si mantenemos que existe un cambio en esta pauta en los enclaves en altura orientalizantes que determine una especificidad en sus funciones como meramente estratégicas, lo cierto es que lo limitado de los restos conservados, escasos materiales en superficie y en algunos casos restos de fortificaciones, no permite ahondar en su determinación. Por ello, proponemos aplicar unos modelos interpretativos menos rígidos, debiendo entenderse que todos estos enclaves desarrollarían diversa funcionalidad, tal y como ocurre en las economías mixtas, en las cuales continua teniendo importancia la complementariedad económica de base subsistencial, a pesar de que se constaten evidencias de la existencia de tendencias que rompen dichas pautas hacia una cierta especialización de los asentamientos y que se detecte un consumo diferencial de algunos bienes en este tipo de enclaves, tal y como denota la existencia de fragmentos de cuenco- trípode en el caso de Penya Fongua, respecto al resto de los enclaves que circundan el poblado de la Penya Negra (vid. supra).

\section{Conclusiones}

Hemos intentado presentar una primera aproximación al estudio de la estructura económica y comercial orientalizante de la Vega Baja del Segura, revisando los modelos y argumentos arqueológicos propuestos hasta el momento. Planteamos además la posibilidad de la existencia ya en estos momentos de una economía política en la zona, organizada y desarrollada principalmente por las poblaciones locales, que se verá complementada y dinamizada por la llegada de los fenicios a la zona, desarrollando un proceso intenso de interacción socio-económica y cultural de cariz integrador, que se manifiesta en la numerosa presencia de hibridaciones culturales visibles en la cultura material, o en la coexistencia de registro cerámico a torno con manual. Además se debe superar la lectura culturalista que trata de categorizar a dos poblaciones diferenciadas y realizar una lectura conjunta de las manifestaciones arqueológicas orientalizantes, ya que los indicadores arqueológicos dan indicios de

131 Grau y Moratalla, op. cit, 2001; Moratalla, op. cit, 2004.

132 Pernas García, op. cit, 2006. 
una gran integración en toda el área, que provoca que tempranamente se convierte en una zona productora, además de que intensifique la explotación económica del entorno, dada la existencia de un flujo constante de intercambio y contacto con otras áreas mediterráneas y sobre todo, a través de los circuitos terrestres que comunican la zona con los dos principales valles, uno al norte, el Vinalopó, y otro al sur la parte alta del Valle del Segura. Se debería valorar más el estudio de estas zonas intermedias o prelitorales en el análisis de las redes económicas de intercambio interior-costa, que quizá tuvieron una mayor relevancia regional en el flujo de intercambio y la dinámica comercial que los circuitos costeros, centrados en el intercambio a larga distancia, y en la navegación de cabotaje entre áreas próximas. Es decir, quizá su análisis nos permita documentar mejor la integración socioeconómica y cultural del territorio levantino. En cualquier caso, nuestro proyecto de investigación cree imprescindible, cambiar la óptica de aproximación, normalmente centrada en analizar el periodo orientalizante a través de la presencia fenicia y el desarrollo de sus dinámicas socioeconómicas. Pensamos, que a fin de obtener una visión más completa de la génesis y desarrollo de una economía regional orientalizante en la zona meridional de la facha da oriental peninsular, se debería ahondar en el estudio de las estructuras económicas del Bronce Final regional para poder evaluar mejor la incidencia y la caracterización de la presencia fenicia en estas áreas.

\section{Bibliografía}

ABAD, L. y SALA, F., Eds., El poblamiento ibérico del Bajo Segura, Publicaciones del Gabinete de Antigüedades de la R.A.H., Bibliotheca Arcaheologica Hispana; 12, Madrid, 2001.

ABULAFIA, D., 2006, «Mediterraneans», en Rethinking the Mediterranean, Oxford Press, London, 2006, pp.64-93.

ALMAGRO-GORBEA, M., «El Pic dels Corbs, de Sagunto, y los campos de urnas del NE. de la Península Ibérica» Saguntum, nº 12, Valencia, 1977, pp. 89-144.

ALMAGRO-GORBEA, M., «Arqueología e Historia Antigua: el proceso proto-orientalizante y el inicio de los contactos de Tartessos con el Levante Mediterráneo», Anejos de Gerión, 2, 1989, pp. 277-288.

ALMAGRO-GORBEA, M., «El mundo orientalizante en la Península Ibérica», II Congreso de Internationale de Studi Fenici e Punici, Vol. II, CNDR, 1991, 573599.

ARANEGUI GASCÓ, C., «Las influencias mediterráneas al comienzo de la Edad del Hierro», Monografías del laboratorio de Arqueología de Valencia, $\mathrm{n}^{\circ}$ 1, Valencia, 1981, pp. 41-66. 
ARTEAGA, O,» Perspectivas espacio-temporales de la colonización fenicia occidental. Ensayo de aproximación», Iberos, I Jornadas sobre el Mundo Ibérico, Jaén, 1986, pp. 225-228

ARTEAGA, O y SERNA, M.R., «Los Saladares: Un yacimiento proto-histórico en la región del Bajo Segura», Crónica del XII CNA, 1973, pp. 437-450.

ARTEAGA, O y SERNA, M.R., «Influjos fenicios en la región del Bajo Segura», XIII C.N.A., Zaragoza, 1975, pp. 737-750.

ARTEAGA, O y SERNA, M.R., «Las primeras fases del poblado de los Saladares», Ampurias, t. 41-42, 1980, pp. 65-137.

AUBET, M. E., Tiro y las colonias fenicias de Occidente. Ed. Crítica, Barcelona, 1997.

AZUAR, R., ROUILLARD, P., GAILlEDRAD, E., MORET, P., SALA SELLÉS, F. y BADIE, A. «El asentamiento orientalizante e ibérico antiguo La Rábita, Guardamar del Segura (Alicante). Avance de las excavaciones 1996-1998», T.P., 55, nº 2, C.S.I.C., 1998, pp. 111-126. Madrid.

AZUAR, R.; ROUILLARD, P.; GAILLEDRAT, E.; MORET, P. y SALA SELLÉS, F. «L'établissement orientalisant et ibérique ancien de «La Rábita», Guardamar del Segura (Alicante, Espagne)», en Scripta in honorem. Enrique Llobregat Conesa. I. E. A., Alicante, 2000, pp. 265-285.

BLÁZQUEZ, J.M., «Tres arqueólogos españoles del siglo XX: Los profesores A. García y Bellido, A. Blanco y J. Maluquer de Motes», VII Jornadas de Arte. Historiografía del arte español en los siglos XIX y XX, Madrid, 1995, 192-193.

BLÁZQUEZ, J.M. «Evolución del concepto orientalizante en los últimos 50 años de investigación hispana», en S. Celestino y J.Jimenez, Eds., El periodo orientalizante. Actas del III Simposio de Arqueología de Mérida: protohistoria del Mediterráneo Occidental, Anejo de A.E.A., 35, Madrid, 2005, pp. 126-148.

BLÁZQUEZ, A.M., USERA, J., FERRER, G., «Foraminíferos fósiles de un sondeo de la albufera cuaternaria de Elche-Sta Pola (Alicante, España): paleoecología e interpretación medioambiental», Geoarqueología i Quaternari Litoral, Memorial Pilar Fumanal, Valencia, 1999, pp. 309-320.

BOWERSOCK, G.W., «The East-West orientation of Mediterranean Studies and the meaning of North and South in Antiquity», Rethinking the Mediterranean, Oxford Press, London, 2006, pp. 167-178.

EARLE, T. K., «Chiefdoms in archaeological and ethnohistorical perspective». Annual Review of Anthropology, vol. 16, 1987, pp. 279-308.

EARLE, T. K., ed., «Chiefdoms: Power, Economy, and Ideology, Revue française d'antropologie», No 137, 1996.

DOMÍNGUEZ PÉREZ, J. C., «El «Karum» asirio como modelo de colonia comercial inicial: implicaciones teóricas sobre su aplicación a las fundaciones fenicias 
orientales», Revista atlántica-mediterránea de prehistoria y arqueología social, $\mathrm{N}^{\circ}$ 7, 2004-2005, pp. 79-107.

DEMARRAIS, E.; JAIME CASTILLO, L.; EARLE, T. K., ed., «Ideology, materialization and Power Strategies», Current Anthropology, Vol. 37, $\mathrm{n}^{\circ}$ 1, 1996, pp. 15-31.

EARLE, T. K., «Archaeology, Property, and Prehistory», Annual Review of Anthropology, 29, 2000, pp.39-60.

FIGUERAS PACHECO, F., Historia de Guardamar del Segura en la Edad Antigua. I. E.A. Alicante, 1957.

FLETCHER, D., «La Edad del Hierro en el Levante español», IV Congreso Internacional de Ciencias Prehistóricas y Protohistóricas, Madrid, 1954.

FRANKENSTEIN, S., Arqueología del colonialismo: el impacto fenicio y griego en el sur de la Península Ibérica y el suroeste de Alemania, Ed. Crítica, Barcelona, 1997, $386 \mathrm{p}$.

GARCÍA y BELLIDO, Fenicios y cartagineses en Occidente, Madrid, 1942.

GARCIA MENÁRQUEZ, A., «El Cabezo Pequeño del Estaño: Notas preliminares sobre un poblado protohistórico en Guardamar del Segura», Azarbe 4. Guardamar del Segura, 1989.

GARCIA MENÁRQUEZ, A. «El Castillo de Guardamar. Nuevos datos sobre el poblamiento ibérico en la desembocadura del río Segura», Alebus, 2-3: 68-96. Elda, 1992-1993.

GARCIA MENÁRQUEZ, A. «El Cabezo Pequeño del Estaño, Guardamar del Segura. Un poblado protohistórico en el tramo final del río Segura», Actas del coloquio El mundo púnico. Historia, sociedad y cultura. Biblioteca básica murciana: extra 4, Cartagena, 1994, pp. 269-280.

GARCÍA SANJUÁN, L., Introducción al reconocimiento y análisis arqueológico del territorio, Ariel, 2005.

GIL-MASCARELL BOSCÁ, M., «Bronce Tardío y Bronce Final en el País Valenciano», Monografías del laboratorio de Arqueología de Valencia, ${ }^{\circ}{ }^{1}$, Valencia, 1981, 9-39.

GODELIER, M. (coord.), ¿Es posible una antropología económica?, Antropología y economía. Anagrama. Barcelona, 1976.

GONZÁLEZ PRATS, A., «El Tesorillo de tipo orientalizante de la Sierra de Crevillente», Ampurias, 38-40, Barcelona, 1976, pp. 349-360.

GONZÁLEZ PRATS, A., «El componente tipológico griego en el ambiente cerámico de Peña Negra II (675 - 550 a.C.)», Lucentum, I, Alicante, 1982, pp. 93-113.

GONZÁLEZ PRATS, A., Estudio arqueológico del poblamiento antiguo de la Sierra de Crevillente (Alicante). Anejo I de Lucentum, Universidad de Alicante, Alicante, 1983. 
GONZÁLEZ PRATS, A., «Los nuevos asentamientos del final de la Edad del Bronce: problemática cultural y cronológica», Arqueología del País Valenciano: Panorama y perspectivas. Edición internet. Valencia, 1985.

GONZALEZ PRATS, A., «Las importaciones y la presencia fenicia en la Sierra de Crevillente (Alicante)», Aula Orientalis, 4, Barcelona, 1986, pp. 279-302.

GONZALEZ PRATS, A., «Dos Bronces fenicios de la Colección Candela: Aportación al conocimiento de la orfebrería e iconografía orientalizante de la Península Ibérica», en Tartessos. Arqueología Protohistórica del Bajo Guadalquivir, Barcelona, 1989, pp. 411-430.

GONZÁLEZ PRATS, A., Nueva luz sobre la protohistoria del Sudeste. Universidad de Alicante, Alicante, 1990.

GONZALEZ PRATS, A., «La presencia fenicia en el Levante Peninsular y su influencia en las comunidades indígenas», IV Jornadas de Arqueología feniciopúnica, Ibiza, 1991, $109-118$.

GONZÁLEZ PRATS, A., «La Fonteta. El asentamiento fenicio de la desembocadura del río Segura (Guardamar, Alicante, España). Resultados de las excavaciones de 1996 - 1997», R. d S.F., Roma, 1999, 191 - 228.

GONZALEZ PRATS, A., «Informe preliminar de la $4^{\text {a }}$ Campaña de excavaciones arqueológicas en la colonia fenicia de La Fonteta (Guardamar del Segura, Alicante), [http://www.labherm.filol.csic.es], acceso 29-VIII-2004, Internet-Alicante. 2000.

GONZALEZ PRATS, A., La necrópolis de les Moreres, Crevillente, Anejos de Lucentum, 2002.

GONZALEZ PRATS, A., «Balanç de vint-i-cinc anys d'investigació sobre la influència i presència fenícia a la provincia d'Alacant», Dossier, Fenicis i Púnics als Paísos Catalans, Ramon Torres, J. (Coord.), Fonaments, 12, 2005, pp. 41-64.

GONZALEZ PRATS, A., «Rasgos arquitectónicos y urbanísticos de La Fonteta», J.L. López Castro, Ed., Las Ciudades fenicio- púnicas en el Mediterráneo Occidental, C.E.F y P., Almería, 2008.

GRAU MIRA, I. y MORATALLA JÁVEGA, J., «Interpretación socioeconómica del enclave», en L. ABAD y F. SALA Eds., El poblamiento ibérico del Bajo Segura, Publicaciones del Gabinete de Antigüedades de la R.A.H., Bibliotheca Arcaheologica Hispana; 12, Madrid, 2001, pp. 189-195.

GRAU MIRA, I., SALA SELLÉS, F., ABAD CASAL, L., La Contestania Ibérica, treinta años después, Universitat d' Alacant, 2005.

HARRIS, W. V., «The Mediterranean and Ancient History» en Rethinking the Mediterranean, Oxford Press, London, 2006, pp.4.

HERNÁNDEZ PÉREZ, M. S., «El agua que fecunda la tierra: Uso y gestión del agua en la Prehistoria del Sureste», La cultura del agua en la cuenca del Segura, Antonio Gil Olcina (dir.), 2004, pp. 45-58. 
HERNÁNDEZ PÉREZ, M. S., «La Contestania ibérica desde la prehistória»,La Contestania ibérica, 20 años después, Abad et alii, coord, Alicante, 2005.

HORDEN, P. and PURCELL, N., The Corrupting Sea The Corrupting Sea: A Study of Mediterranean History, 2000.

JIMÉNEZ AVILA, F. J. Y CELESTINO PÉREZ, S. (coord.), El periodo orientalizante: Actas del III Simposio Internacional de Arqueología de Mérida, Protohistoria del Mediterráneo Occidental, Mérida, 2005.

JOHNSON, A. W. y EARLE, T. K, La evolución de las sociedades: desde los grupos cazadores-recolectores al estado agrario, Ariel, 2003.

KAPLAN, D., «La controversia formalistas-sustantivistas de la antropología económica: reflexiones sobre sus amplias implicaciones». En Godelier, M. (Coord.) ¿Es posible una Antropología económica?, Antropología y economía. Anagrama. Barcelona, 1976.

LAFUENTE VIDAL, J., «Importante hallazgo arqueológico. ¿Una necrópolis cartaginesa?. Primeras impresiones», Noticiero del Lunes, Alicante, 1928, p. 482.

LAFUENTE VIDAL, J., «La necrópolis ibérica de El Molar (Provincia de Alicante)», B.R.A.H., 94, Madrid, 1929, pp. 617-632.

LAFUENTE VIDAL, J., Alicante en la Edad Antigua, Alicante, 1957.

LE MEAUX, H. Y SÁNCHEZ DE PRADO, M ${ }^{\mathrm{a}}$ D., «Le mobilier non céramique», en P. Rouillard, E. Gailledrat et F. Sala, Eds, L'establissement protohistorique de La Fonteta (fin VIII - Fin VI siecle av. J.C., Casa Velzquez Vol. 96, Madrid, 2007, pp. 327.

LLOBREGAT CONESA, E.A., «Orígenes de la cultura ibérica en la Contestania», Ampurias, 38-40, Simposi Internacional Els Origens del món ibèric, 1976-1978, pp. 61-74.

LLOBREGAT CONESA, E.A., «Presencia fenícia al País Valencià: novetats i balanç provisional», Fonaments, 8, 1992, pp. 171-182.

LÓPEZ CASTRO, J.L., «La colonización fenicia en la Península Ibérica: 100 años de investigación», en La colonización fenicia en el sur de la Península Ibérica. 100 años de investigación, Granada, 1992, pp. 11-80.

LÓPEZ CASTRO, J.L., «Formas de intercambio de los fenicios occidentales en época arcaica»,

Intercambio y comercio preclásico en el Mediterráneo, actas del I coloquio del CEFYP, Madrid, 9-12 de noviembre, 1998,coord. María Pilar Fernández Uriel, Fernando López Pardo, Eduardo Carlos González Wagner, 2000, pp. 123-136.

MARTÍN, G., La supuesta colonia griega de Hemeroskopeion. Estudio arqueologico de la zona de Dénia-Jávea. P.L.A.U.V., 3, Valencia, 1968.

MARTÍNEZ VEIGA, U., Antropología económica: conceptos, teorías, debates. Barcelona: Icaria, 1990. 
MAUSS, M. Ensayo sobre el don la forma y la razón del intercambio en las sociedades arcaicas, 1925.

MEDEROS MARTÍN, A. «Fenicios evanescentes. Nacimiento, muerte y redescubrimiento de los fenicios en la P. Ibérica. I (1780-1935)», Saguntum, 33, Valencia, 2001, pp. 37-48.

MEDEROS MARTÍN, A., «La metamorfosis de Villena. Comercio de oro, estaño y sal durante el Bronce Final I entre el Atlántico y el Mediterráneo (1625-1300 a.C.)», T.P. 52, nº 2, Madrid, 1999, pp. 1-22.

MORATALlA, J., «El territorio Meridional de la Contestania», La Contestania Ibérica, 20 años después, Alicante, 2005a, pp. 91-117.

MOSCATI, S., I fenici e Cartagine, Torino, 1972.

NIEMEYER, C.H., Ed., Phöenizer in West, Madrider Beïtrage, 8, Madrid, 1982. PERNAS GARCÍA., S., La investigación de la Protohistoria antigua: el caso de las comarcas centrales y meridionales del Levante Peninsular, Memoria de Licenciatura inédita, Universidad de Alicante, 2005.

PERNAS GARCÍA, S., «La problemática definición de los inicios del Bronce Final», Alebus, Revista del museo Arqueológico de Elda (Alicante), original entregado en enero de 2006 y aceptado el mismo mes, publicación en prensa, Elda, 2006.

POLANYI, K., ARENSBERG, C. Y PEARSON, H., Comercio y mercado en los imperios antiguos, Labor. Barcelona.1976.

POVEDA NAVARRO, A.M. «Primeros datos sobre las influencias fenicio-púnicas en el corredor del Vinalopó (Alicante)», en A.González Blanco, J.L. Cuchillos y M. Molina (eds.): El mundo púnico. Historia, sociedad y cultura, Biblioteca Básica Murciana, Extra, 4: 489-502. Murcia, 1994.

POVEDA NAVARRO, A.M. «Penetración cultural fenicia en el territorio indígena del valle septentrional del Vinalopó (Alicante)», en Mª. E. Aubet y M. Barthéley (eds.): IV Congreso Internacional de Estudios Fenicios y Púnicos (Cádiz 1995), IV, Universidad de Cádiz 1863-1874. Cádiz, 2000.

RAMON J., Las ánforas fenicio púnicas del Mediterráneo Central y Occidental, Barcelona, 1995.

RENFREW, C., «Alternative models for Exchange and spatial distribution»,en Exchange Systems in Prehistory, eds, T.K. Earle y J.E. Ericsson, Academic Press, London, 1977, pp.71-90.

RENZI, M., Estudio tipológico y funcional de las toberas del yacimiento de la Fonteta (Guardamar del Segura, Alicante), T P,64, No 1, Enero-Junio 2007, pp. 165-177.

REMEDIOS SÁNCHEZ, S., «El papel del templo y la aristocracia en la estructura social de los yacimientos fenicios peninsulares en época Arcaica», Actas del $\mathrm{V}$ Encuentro de Jóvenes Investigadores: Historia Antigua, edición nacional: ideología, estrategias de definición y formas de relación social en el mundo 
antiguo, coord. Fernando Echeverría Rey, María Yolanda Montes Miralles, 2006, pp. 113-121.

ROUILLARD, P., Les grecs et la peninsule iberique: du VIIIe au IV e siècle avant

Jésus-Christ. Publications du Centre Pierre Paris Casa de Velásquez, Paris, 1991,. ROUILLARD, P., GAILlEDRAT, E., SALA SELLLÉS, F., L'établissement protohistorique de La Fonteta (fin VIIIe - fin VI siècle av. J.-C.). Collection de la Casa de Velázquez, Vol. 96., 2007.

RUIZ ZAPATERO, G., «Las acciones de Campos de Urnas en el País Valenciano», C.P.A.C., 5, Castellón de la Plana, 1978, pp. 243-255.

SENENT IBÁÑEZ, J.J., «En torno a Hemeroskopeion», C.A.S.E., III. Murcia, Cartagena, 1948 pp. 241-243.

SAID, E., Orientalismo, 2003.

SALA SELLÉS, F., «La influencia del mundo fenicio y púnico en las sociedades autóctonas del Sureste peninsular», XVIII Jornadas de Arqueología feniciopúnica, Eivissa, 2004, pp. 57-102.

SALA SELLÉS, F., «La cerámique grise», en Rouillard, P., Gailledrat, E., Sala Sellés, F., L'établissement protohistorique de La Fonteta (fin VIIIe - fin VI siècle av. J.-C.). Collection de la Casa de Velázquez, Vol. 96., 2007, pp. 199-211.

SCHUBART, H. y ARTEAGA, O. (1986): «El mundo de las colonias fenicias occidentales», Homenaje a Luis Siret. Cuevas del Almanzora, 1984: 449-521. Sevilla.

TARRADELL, M., «Sobre la última época de los fenicios en Occidente», Zephyrus IV. Homenaje a César Morán Bardón, 1953, pp. 511-515.

TARRADELL, M., «La cultura del Bronce Valenciano. Nuevo ensayo de aproximación», P. L. A.V., 6, Valencia, 1969.

TARRADELL, M., El País Valencià del Neolítico a la iberización, Anales de la Universidad de Valencia, vol. XXXVI, q. II, Valencia, 1962-1963.

UROZ, H., El programa iconográfico religioso de la «Tumba del orfebre» de Cabezo Lucero (Guardamar del Segura, Alicante), Monografías de Arte Ibérico de El Cigarralero, 2006, pp. 166-167.

VV.AA., Los fenicios en Andalucía, 1985.

VAN DOMMELEN, P., «Colonial matters. Material Culture and postcolonial theory in Colonial Situations», C. Tilley, W. Keane, S. Kuechler, M. Rowlands, P. Spyer, Eds., Handbook of material culture, SAGE, London, pp. 104-124.118-119.

VIVES-FERRÁNDIS, J., Negociando encuentros, situaciones coloniales $e$ intercambios en la costa oriental de la Península Ibérica (ss. VIII-VI a.C.), Cuadernos de Arqueología Mediterránea, 12, Barcelona, 2005.

VIVES-FERRÁNDIS, J.» Trípodes fenicios entre el Ebro y el Segura: nuevas perspectivas de estudio», El periodo orientalizante: Actas del III Simposio 
Internacional de Arqueología de Mérida, Protohistoria del Mediterráneo Occidental, coord. por F. J. Jiménez Avila, Sebastián Celestino Pérez, Vol. 2, 2005b pp. 1351-1362.

VIVES-FERRÁNDIS, J., «Notas historiográficas sobre los estudios fenicios en el País Valenciano», A.P.L., XXVI, Valencia, 2006, pp. 293-321;

WAGNER, C.G. Y ALVAR, J., «Fenicios en Occidente: la colonización agrícola», RSF XVII, 1989, pp. 61-102. 